\title{
An Assessment of Flap and Main Landing Gear Noise Abatement Concepts
}

\author{
Mehdi R. Khorrami, ${ }^{*}$ William M. Humphreys, Jr., ${ }^{\dagger}$ and David P. Lockard \\ NASA Langley Research Center, Hampton, Virginia, 23681
}

\begin{abstract}
A detailed assessment of the acoustic performance of several noise reduction concepts for aircraft flaps and landing gear is presented. Consideration is given to the best performing concepts within the suite of technologies that were evaluated in the NASA Langley Research Center 14- by 22-Foot Subsonic Tunnel using an $18 \%$ scale, semi-span, high-fidelity Gulfstream aircraft model as a test bed. Microphone array measurements were obtained with the model in a landing configuration (flap deflected $39^{\circ}$ and the main landing gear deployed or retracted). The effectiveness of each concept over the range of pitch angles, speeds, and directivity angles tested is presented. Comparison of the acoustic spectra, obtained from integration of the beamform maps between the untreated baseline and treated configurations, clearly demonstrates that the flap and gear concepts maintain noise reduction benefits over the entire range of the directivity angles tested.
\end{abstract}

\section{Nomenclature}

$\begin{array}{ll}\text { AOA } & =\text { Angle of attack, degrees } \\ f & =\text { Frequency, Hz } \\ l & =\text { Reference length scale (mean aerodynamic chord) } \\ \mathrm{M} & =\text { Mach number } \\ S t & =\text { Strouhal number } \\ U_{\mathrm{o}} & =\text { Reference (freestream) velocity } \\ \theta & =\text { Flyover angle, degrees }\end{array}$

\section{Introduction}

Mitigation of community noise resulting from civil aircraft operations is an important goal for NASA. Airframe noise is a prominent component of aircraft noise during approach and landing. Continuous advancement in quieter propulsion technologies has brought renewed attention to the design and development of low-noise airframe components. ${ }^{1}$ Prior aeroacoustic studies (flight tests and model-scale experiments) have identified the prominent sources of airframe noise. ${ }^{1}$ The primary sources are the undercarriage and high-lift devices such as the wing leading-edge slats and flaps. ${ }^{2-11}$ The present study is part of a comprehensive program, sponsored by NASA's Environmentally Responsible Aviation (ERA) project, focused on the advancement and maturation of airframe noise reduction technologies that will minimize aircraft noise footprints on the ground while maintaining aerodynamic efficiency.

The present work is an extension of an earlier study of airframe noise that was performed at the NASA Langley Research Center (LaRC) 14- by 22-Foot Subsonic Tunnel (14x22), with the facility operating in its open-jet (wall) acoustic configuration, during February - March of 2013. Using a high-fidelity $18 \%$ scale, semi-span model of a Gulfstream aircraft as a test bed, numerous noise abatement technologies targeting the sources associated with flap tips and main landing gear were evaluated. ${ }^{12,13}$ The aeroacoustic performance and effectiveness of the noise mitigation concepts were demonstrated via microphone array measurements with the aircraft model in a landing configuration with the flap deflected $39^{\circ}$ and the main landing gear installed (on) or removed (off). Data were acquired at Mach numbers of $0.16,0.20$, and 0.24 over directivity angles spanning $56^{\circ}$ and $116^{\circ}$, with $90^{\circ}$ representing the overhead direction. The majority of the data were acquired with the semi-span model at an angle of attack (AOA) of $3^{\circ}$. Limited data were also taken at AOAs of $4^{\circ}$ and $5^{\circ}$.

A detailed description of all the tested noise reduction concepts is given in Ref. 12. That report was limited to the initial analysis of acoustic results for $\mathrm{M}=0.2$ and the $90^{\circ}$ (overhead) direction. In the present work, only those concepts

\footnotetext{
* Aerospace Engineer, Computational AeroSciences Branch, Associate Fellow AIAA

† Assistant Branch Head, Advanced Measurements and Data Systems Branch, Associate Fellow AIAA

* Aerospace Engineer, Computational AeroSciences Branch, Senior Member AIAA
} 
that achieved good acoustic performance have been selected for further study. The goal is to assess whether the noise reduction benefits for the concepts are maintained over the range of pitch angles, speeds, and directivity angles tested.

\section{Experimental Apparatus and Test Data}

The tested model was an $18 \%$ scale, semi-span, high-fidelity replica of a Gulfstream aircraft. The model includes a fuselage, wing, flap, flow-through nacelle, and main landing gear (Fig. 1). The model is 185.4 in (4.709 m) long (nose to tail) with a span of 104.5 in $(2.654 \mathrm{~m})$ (wind tunnel floor to the tip of the winglet). A full description of the model is given Refs. 14 and 15.

Extensive aeroacoustic testing of the 18\% scale model was conducted in the NASA LaRC 14x22 Subsonic Tunnel. To accommodate acquisition of acoustic data with a traversing microphone array, the tests were conducted with the facility in its open-wall (jet) configuration whereby the ceiling and the side walls of the test section were raised. In addition, the tunnel was operated in a semi-anechoic acoustic mode. In its acoustic configuration, the tunnel background noise was deemed to be acceptable for evaluation of noise reduction concept performance.

The microphone phased array used to obtain the acoustic measurements was comprised of 97 individual Bruel and Kjaer (B\&K) 1/4-inch pressure field microphones flush mounted in a flat fiberglass honeycomb plate with a diameter of $8.05 \mathrm{ft}$. $(2.454 \mathrm{~m})$. The array system was designed for an operational frequency range of approximately $1.5 \mathrm{kHz}-80 \mathrm{kHz}$. The simultaneous sampling rate for all channels was $200 \mathrm{kHz}$ for an acquisition window length of 30 seconds, with all signals band-pass filtered from $400 \mathrm{~Hz}-100 \mathrm{kHz}$. Analysis of the array data was performed using standard frequency-domain delay and sum beamforming coupled with the Deconvolution Approach for the Mapping of Acoustic Sources (DAMAS) algorithm for generation of final noise source map presentations. ${ }^{16,17}$ A customized version of the DAMAS algorithm, called Unified DAMAS (UDAMAS), combining aspects of both the DAMAS and DAMAS-C algorithms, was used for processing. Beamformed and deconvolved source presentation maps for standard 1/12-octave bands spanning a frequency range of approximately $500 \mathrm{~Hz}-30 \mathrm{kHz}$ were generated for the majority of the phased array datasets acquired for the Gulfstream model. See Refs. 12 and 18 for a complete account of the $14 \times 22$ facility, tunnel background noise levels, microphone phased array, and data reduction and analysis process.

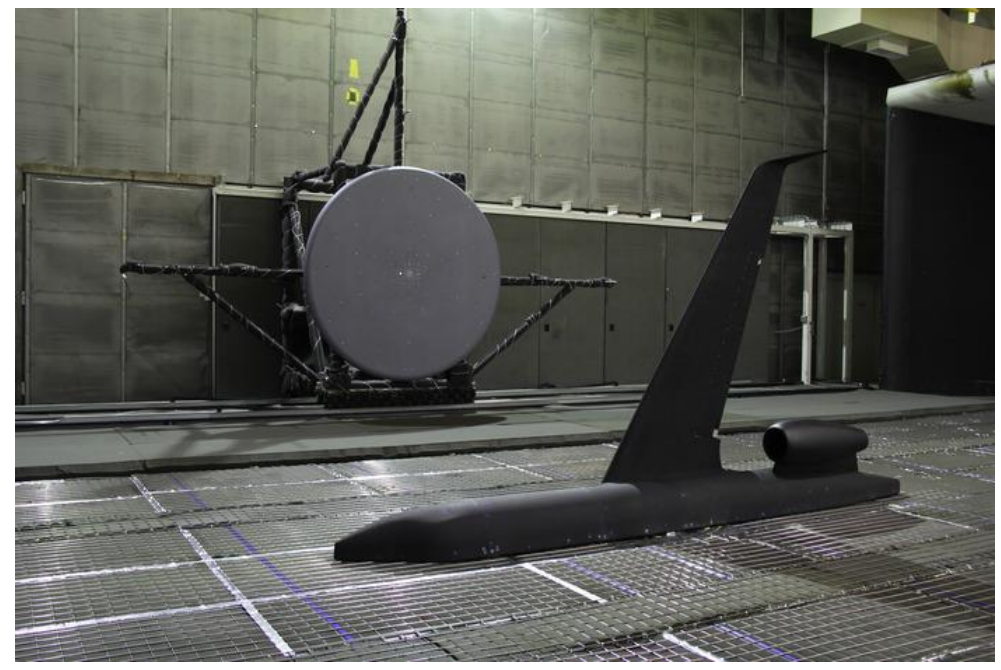

Figure 1. 18\% scale semi-span Gulfstream aircraft model installed in the NASA LaRC 14x22 tunnel.

\section{Noise Abatement Concepts}

During the 2013 aeroacoustic test in the 14x22, numerous concepts for mitigating the noise emanating from the flap tips and main landing gear were tested. For the flap alone, six independent concepts were designed and over thirty permutations of these concepts were fabricated and evaluated. Several fairings of various sizes and shapes were applied to the noise producing components of the main landing gear to reduce the turbulent fluctuations and the resulting unsteady surface pressures. A full description of the entire collection of flap and gear noise abatement technologies that were evaluated is given in Ref. 12. In this paper, the study was limited to the suite of technologies and their permutations that were identified to be the best performers to provide a more in-depth analysis of their measured acoustic behavior. 
For the flap, the four concepts selected for detailed analysis are: 1) porous tip treatment; 2) Flap Edge Noise Reduction Fins (FENoRFins), an array of densely packed comb like structures (fins) in a 3-D arrangement extending inward in the spanwise direction from the flap side edge; 3) FLEXible Side-Edge Link (FLEXSEL); and 4) Reactive Orthotropic Lattice Diffuser (ROLD). All four were designed to affect only a very small fraction of the flap span adjacent to the inboard and outboard tips. Typically, the width of the treated area was scaled with the local maximum flap thickness at each respective tip. The porous tip concept involved substitution of the flap top, bottom, and side surfaces at the tips with a wire mesh skin having a specific resistance. With this design (see Fig. 2a), the treated surfaces would produce a cavity (reservoir) at each tip to allow interaction between the external flow and the internal cavity fluid. Porous tips with four specific surface resistances of 150, 270, 450, and 570 Rayl were tested. For the FENoRFins concept, circular (Fig. 2b) and non-circular cross-section fins were considered. As discussed in Ref. 12, circular cross-section fins with the smallest diameter tested produced the best noise reduction. The FLEXSEL concept is a structural link that uses stretchable (elastomeric) materials for connecting the flap side edge to the wing edge adjacent to the flap (Fig. 2c). The ROLD concept relies on perforation of all three surfaces defining to the flap tip area. The design consists of internal passages or perforations that are orthogonally aligned in all three directions (see Fig. 2d). Passages from each direction intersect, thereby creating a three dimensional lattice structure that is orthotropic in nature. As presented in Ref. 12, acoustic performance of the ROLD concept improved as the size of the perforations (holes) decreased, with the smallest diameter holes producing the highest noise reduction.

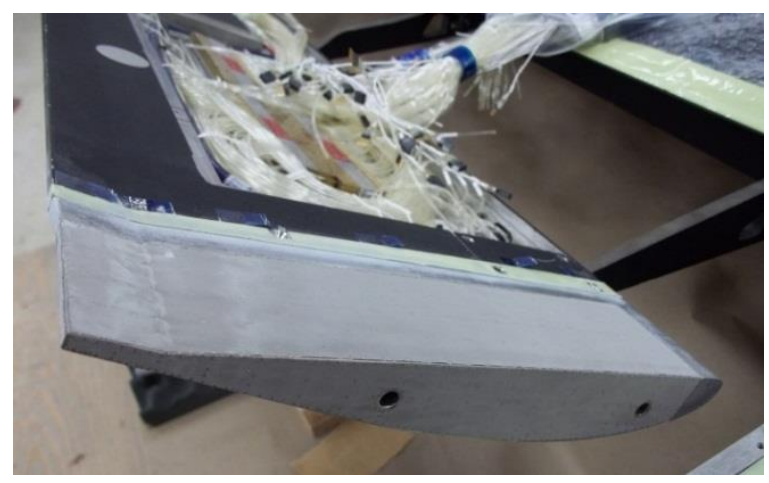

a) porous surface tip

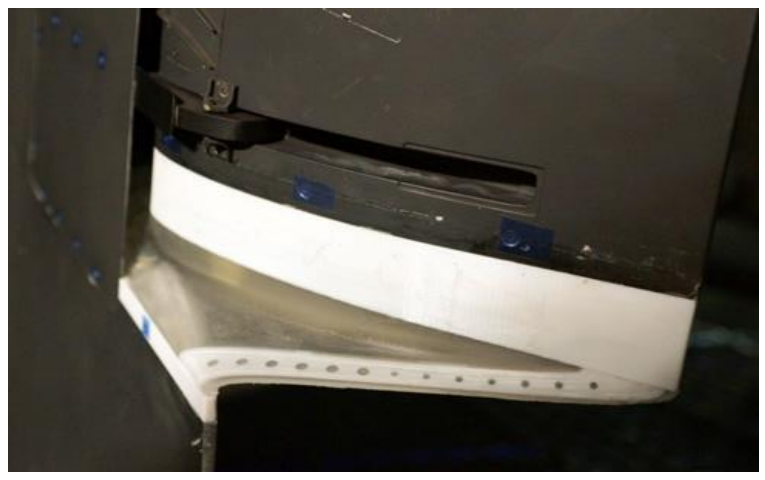

c) FLEXSEL

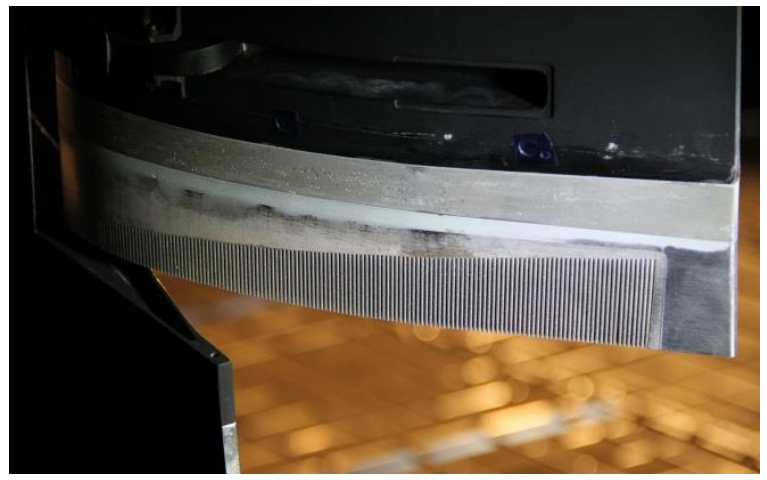

b) FENoRFins

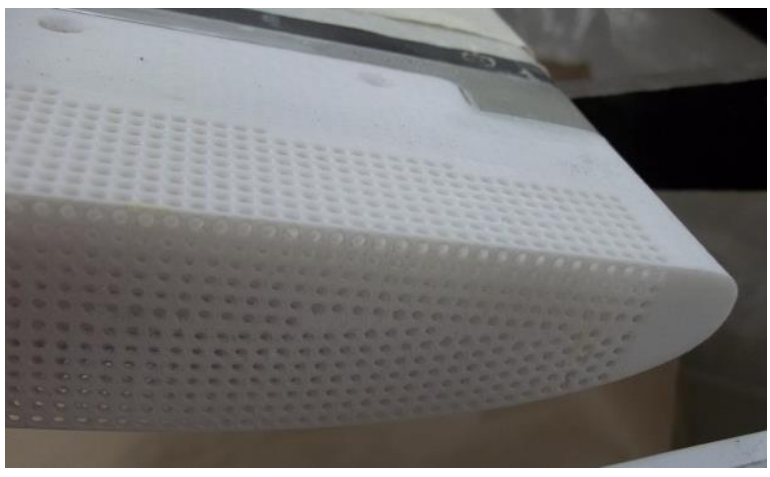

d) ROLD

Figure 2. Flap noise reduction concepts (from Ref. 12).

The best performing landing gear noise reduction concepts involved the application of fairings over various components of the main landing gear to substantially reduce or alter the surface pressure fluctuations. Several small fairings referred to as the "upper fairings" were applied to the upper segment of the gear adjacent to the cavity (wheel well) opening. A fairing that was crucial to the success of the system was the porous knee design that covers the upstream main post and significantly diminishes the noise-producing flow interaction between the front and rear struts. For mitigating the brake noise emanating from the lower portion of the gear, a fairing design that partially covers the frontal portion of the two wheels was applied. Both solid and partially porous versions of the wheel fairing were tested 
and evaluated during the 2013 tunnel entry. These three groups of gear fairings were tested in isolation and concurrently to assess their performance. To reduce the low-frequency noise associated with the landing gear cavity, a stretchable mesh covering the cavity interface (opening) was applied. ${ }^{12}$ As shown in Ref. 12 , the stretchable cavity mesh performed quite well, reducing the low-frequency component of gear noise by more than $2 \mathrm{~dB}$. Figure 3 , taken from Ref. 12, shows the gear fairings and the cavity mesh as installed on the $18 \%$ scale aircraft model. A complete account of the landing gear noise reduction concepts is provided in Ref. 12.

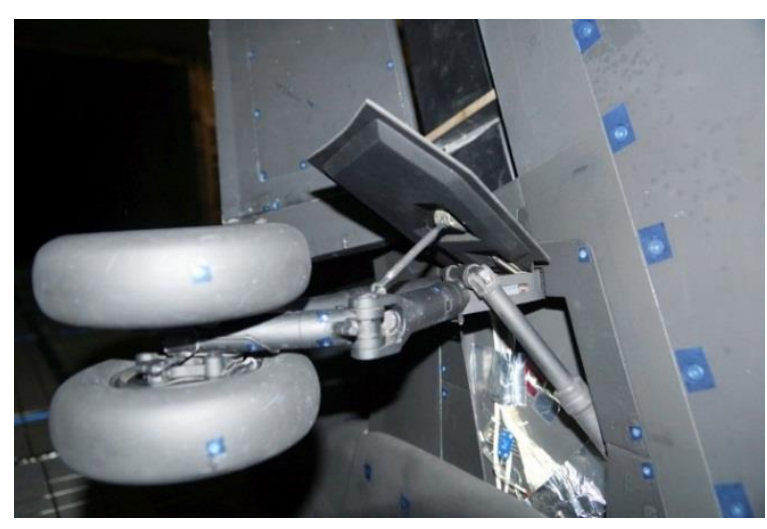

a) Untreated baseline configuration

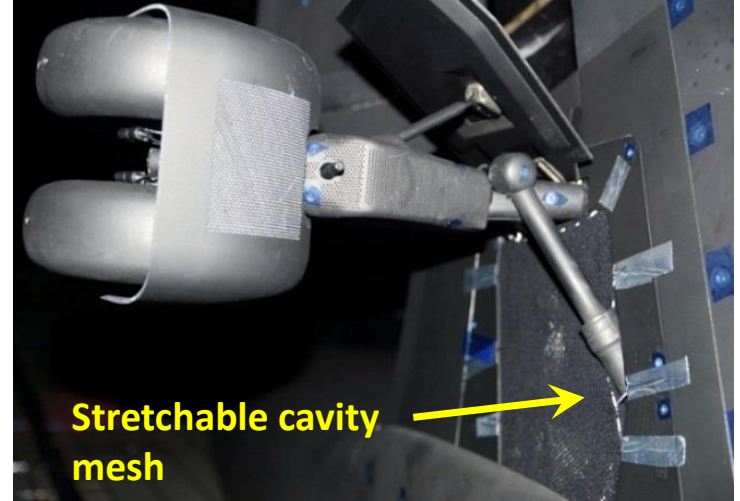

b) All fairings and cavity mesh installed

Figure 3. Frontal view of the main landing gear on $18 \%$ scale aircraft model (from Ref. 12).

Power spectral density (PSD) plots are used in the present study to assess noise reduction concept performance. Construction of the PSD curves requires an accurate spatial integration of the pressure squared values in noise source contour maps at select frequencies. ${ }^{12}$ The frequency resolution for the narrow band calculation of the spectra is 171 $\mathrm{Hz}$. Depending on the noise source region of interest, the integration can be applied to different zones. Four integration regions have been identified for data analysis, as shown in Fig. 4. Region 1 covers an area that contains most of the major airframe noise sources associated with this aircraft. Regions 2 and 3 were specifically devised to ascertain 1) the individual contributions from the flap tips to the overall noise levels and 2) whether a particular flap noise reduction technology is equally effective at both edges. Region 4 covers the entire aircraft model and, therefore, contains some of the high-frequency noise generated primarily upstream of Region 1 and near the tunnel floor by the rough, nonuniform surfaces of the metal cages containing the sound absorbing foam wedges (see Fig. 1). PSD results from Regions 1 and 4 have been used to facilitate direct comparisons with the companion computational simulations. ${ }^{19,20}$, ${ }^{21}$ In this study mostly sample spectra obtained from integrating the UDAMAS contour maps over the wing-flap area (Region 1) are shown. Results based on integration of Regions 2, 3, and 4 are presented occasionally to reinforce certain trends.

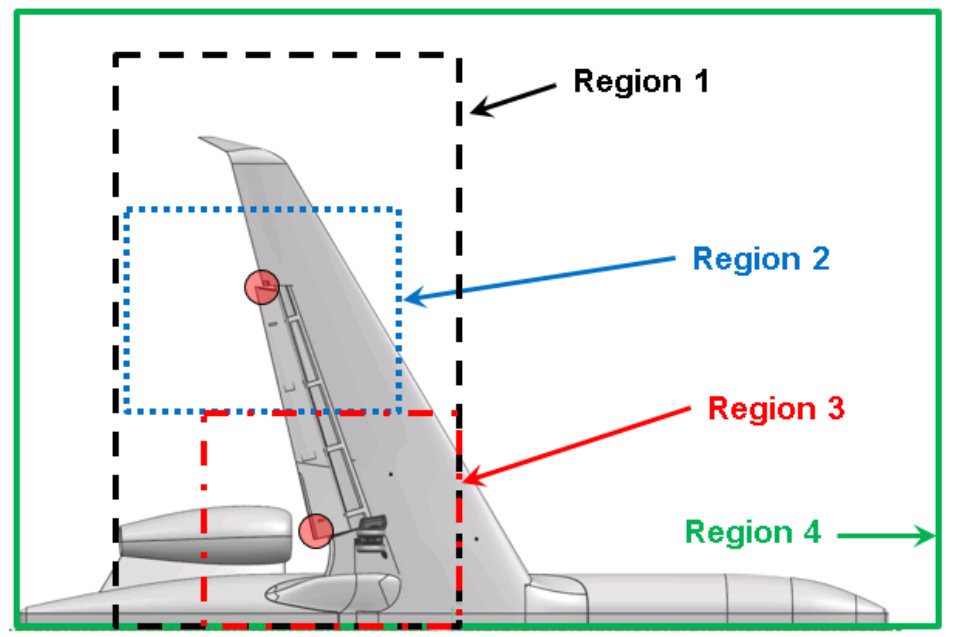

Figure 4. Integration zones used to calculate PSD values (from Ref. 12). 


\section{Results}

The landing configurations consisting of a $39^{\circ}$ flap setting with the main landing gear either installed (on) or removed (off) were the most heavily tested of the $201314 \times 22$ test campaign. A third configuration with a retracted $\left(0^{\circ}\right)$ flap and installed gear, used to evaluate the isolated acoustic performance of the gear noise reduction concepts, is not included in the present study. To assess possible directivity effects on the performance of the noise abatement technologies, acoustic measurements were acquired at flyover directivity angles (prior to shear layer corrections) of $54^{\circ}$, and $60^{\circ}-110^{\circ}$ in $10^{\circ}$ intervals, with $90^{\circ}$ corresponding to the overhead position and aligned with the center of the main landing gear carriage. In the absence of a shear layer (uniform flow from model to array), the directivity range at a flow speed corresponding to Mach 0.2 would be approximately $56^{\circ}-116^{\circ}$. For the present analysis, we use the flyover angles prior to shear layer correction to highlight the directivity trends of farfield noise. The azimuthal emission angle at each flyover position was $14.4^{\circ}$ due to mounting of the array at a fixed height above the tunnel floor. To determine the scaling laws associated with the fluctuating surface pressures and radiating acoustic fields, measurements were obtained at Mach numbers of $0.16,0.20$, and 0.24 , with 0.20 being the nominal speed at which the majority of the data were acquired. The model was set at AOAs of $3^{\circ}, 4^{\circ}$, and $5^{\circ}$.

Sample PSD plots for the $39^{\circ}$ flap deflection with the main landing gear removed baseline configuration are shown in Fig. 5. The results display the PSD levels obtained from integration of Regions 1, 2, 3, and 4 of the beamform map. Because of larger geometrical dimensions, the inboard flap tip produces more noise than the outboard tip at lower frequencies (below $4 \mathrm{kHz}$ ), as expected. The inboard tip also generates more noise at frequencies above $12 \mathrm{kHz}$. The latter observation is quite surprising as one would expect the smaller outboard edge to produce a substantial portion of the higher frequency noise. One possible explanation may be that the cable bundle and brackets in Region 3 (see Fig. 4) are generating more noise than their smaller counterparts in Region 2. In Ref. 12, the flap brackets were shown to generate high-frequency noise. Another possibility is that the proximity of the flow-through nacelle to the inboard flap edge is somehow enhancing the noise generated in Region 3. The beamform maps at certain frequencies seem to indicate that the nacelle is an important source. The spectrum for the outboard tip dominates in the $5 \mathrm{kHz}$ to $11 \mathrm{kHz}$ frequency range because of a broad tonal hump. The tonal feature is caused by the presence of a cavity at the flap outboard tip that spans the entire chord. ${ }^{12}$ The spectrum obtained from integration of the area containing the wing and flap (Region 1) tracks very closely the noise produced by the entire 18\% scale model (Region 4) for frequencies up to about $11 \mathrm{kHz}$. At higher frequencies, the differences in PSD levels between Regions 1 and 4 are caused by the roughness of the acoustically treated floor, as mentioned earlier. This excess noise is unrelated to the airframe noise associated with the $18 \%$ scale model and must be excluded during evaluation of noise reduction concept performance. Therefore, the PSD values obtained from Region 1 will be used as the primary source of information for our comparative analysis. Data from the inboard and outboard flap tips (Regions 2 and 3) will be used sporadically to reinforce some of the observed trends. Unless stated otherwise, all the spectral data presented are based on model scale frequencies.

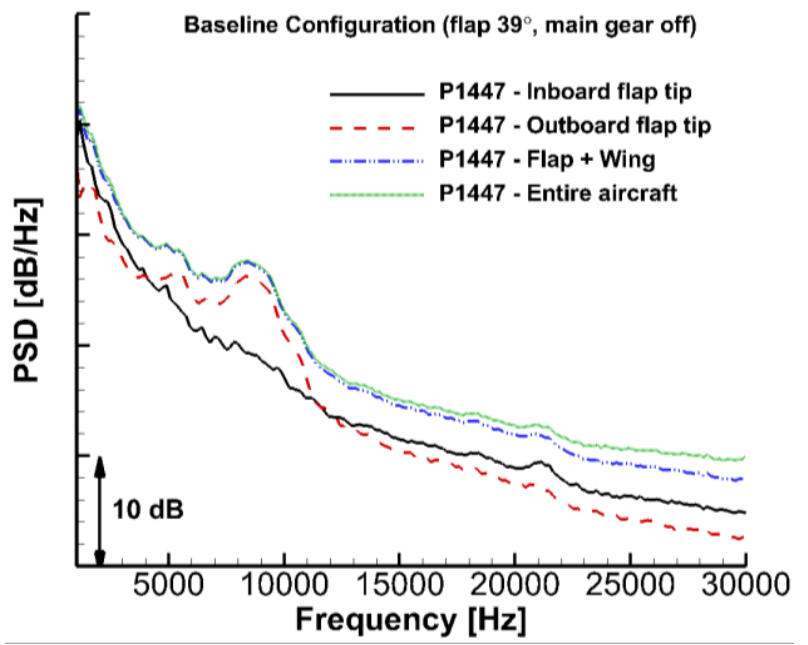

Figure 5. Farfield noise spectra of baseline configuration from the four integration zones of Fig. 4. 


\section{A. $39^{\circ}$ Flap with Main Gear Removed}

The configuration with a flap deflection of $39^{\circ}$ and main landing gear off was used to isolate the side edge noise and to assess the aeroacoustic performance of the flap noise abatement concepts.

\section{AOA Effects}

Most civil transports land with the AOA set within a narrow band that ranges between 3 to 6 degrees. Quasi twodimensional model tests suggest that flap loading is strongly dependent on the flap deflection angle relative to the wing chord line. ${ }^{22}$ As a result, AOA variations during landing will not alter noise generation nor the radiated sound field. The farfield noise spectrum variations with AOA associated with Regions 1,2, and 3 for the baseline configuration are shown in Fig. 6 . The results correspond to the overhead position of $90^{\circ}$. As expected, no significant change is observed for the narrow range tested. The more notable differences occur in the frequency range of $7-10 \mathrm{kHz}$ associated with the broad tonal feature caused by the tip cavity in the flap outboard edge (see Refs. 12-15) and at frequencies greater than $23 \mathrm{kHz}$. Similar trends are observed when the noise reduction concepts are applied to the flap tips. As a sample case, the variations in farfield spectra with AOA when the FLEXSEL concept is installed are shown in Fig. 7. There is hardly any change in the character of the radiated noise fields associated with the three AOA tested.

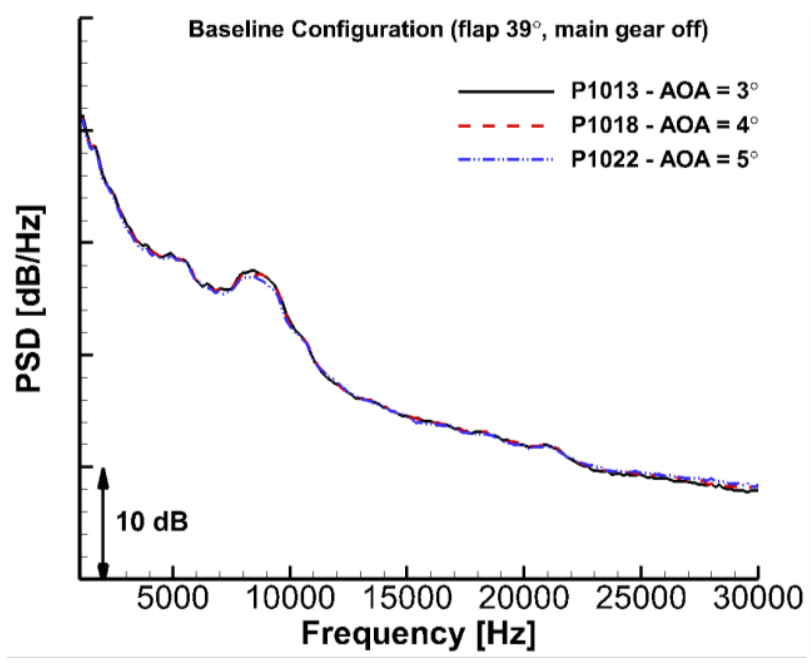

a) Region 1

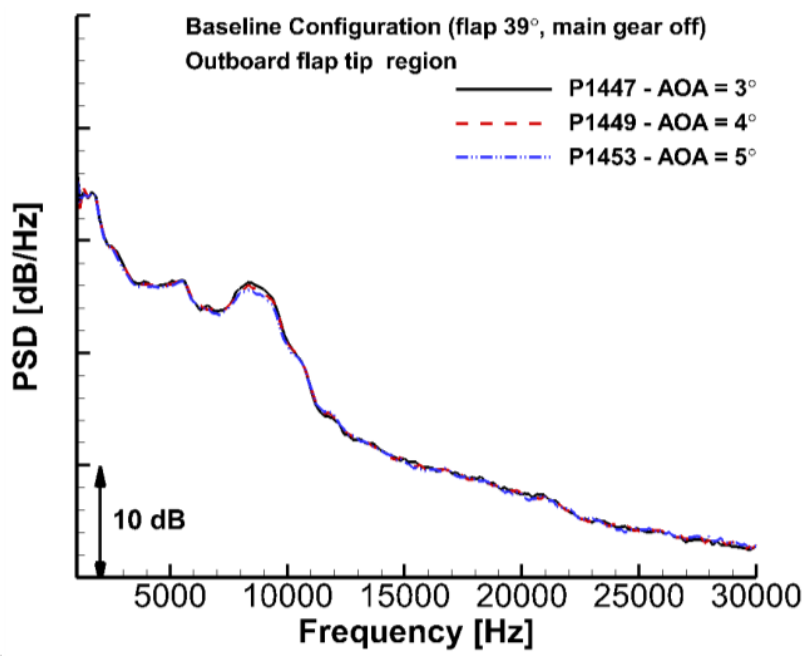

b) Region 2

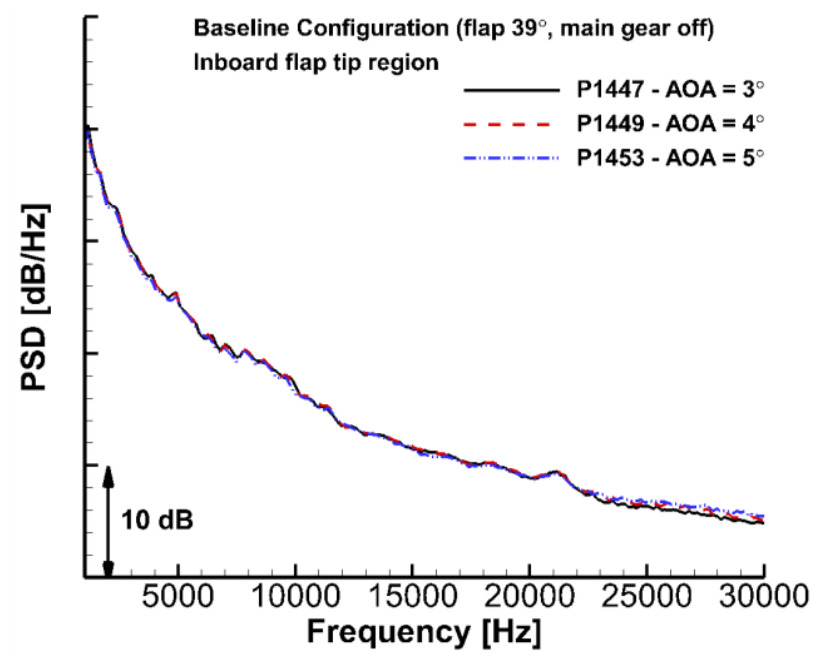

c) Region 3

Figure 6. Effects of AOA variation on farfield noise for baseline configuration (M=0.2, overhead) 


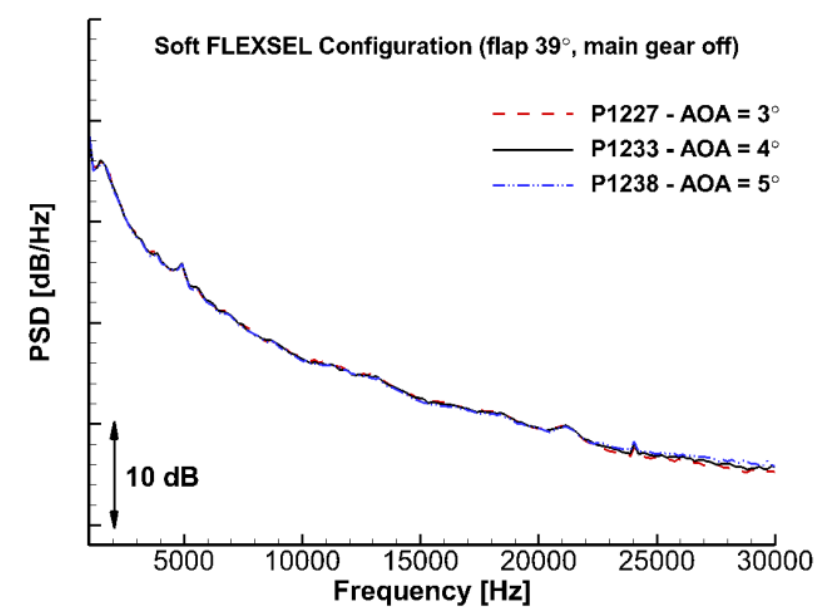

a) Region 1

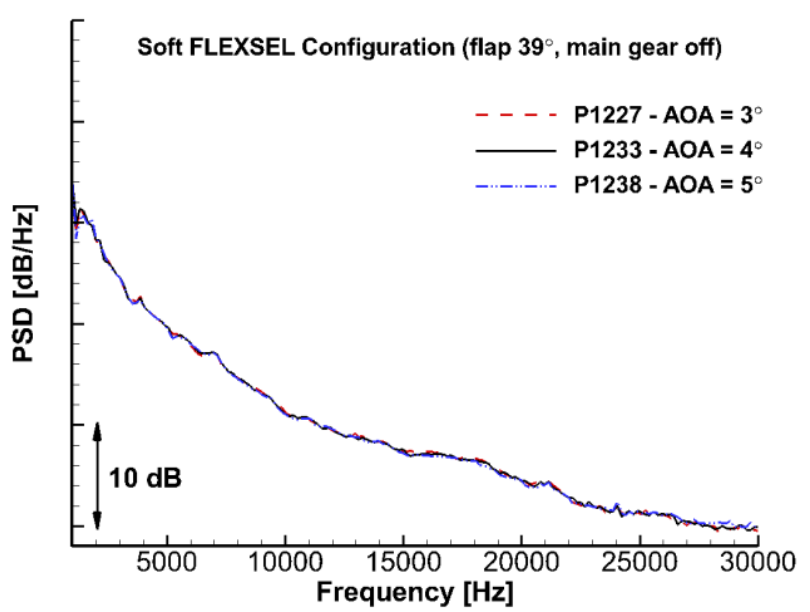

b) Region 2

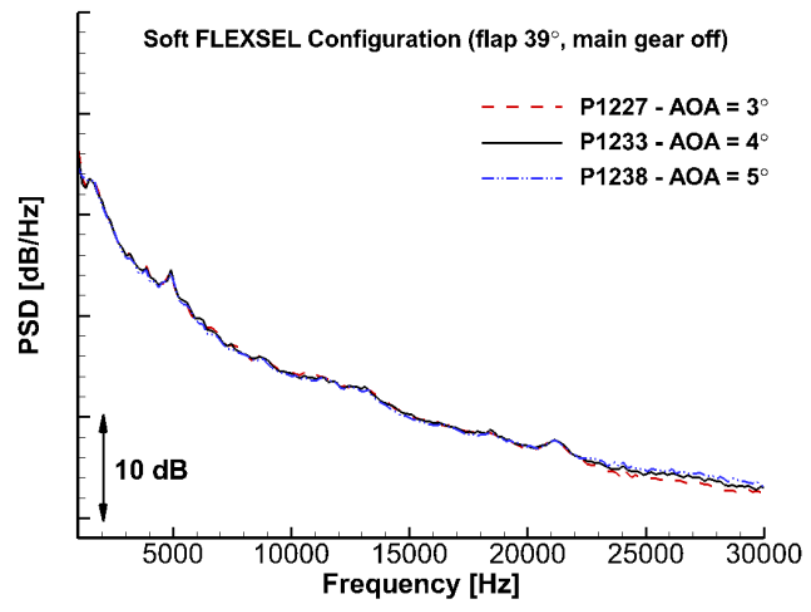

c) Region 3

Figure 7. Effects of AOA variation on farfield noise for FLEXSEL configuration (M = 0.2, overhead)

\section{Velocity Scaling}

Baseline noise spectra for the three tested flow speeds are displayed in Fig. 8. As demonstrated in Ref. 23, oscillations in forces acting on the flap surfaces cause flap side-edge noise to radiate as a dipole. Therefore, a velocity scaling based on $\mathrm{M}^{6}$ and a frequency scaling based on the Strouhal number $\left(S t=f l / U_{o}\right)$ should collapse the three plots shown in Fig. 8a into a single curve. As seen in Fig. 8b, this is not the case. A better collapse is obtained when the frequencies are not scaled at all, as seen in Fig. 8c. Also note from this figure that the broadband component of farfield noise follows $\mathrm{M}^{6}$ normalization relatively well, but the broad tonal hump caused by the cavity at the outboard tip does not. The lack of collapse of this broad tonal feature can be attributed in part to the presence of cavity resonance, which does not display dipole-like radiation characteristics. Surprisingly, a much better data collapse is observed when the original curves (Fig. 8a) are normalized according to $\mathrm{M}^{4}$ with $S t$ scaling, as seen in Fig. 8d. This monopole type scaling produces slightly better results than those shown in Fig. 8c.

To demonstrate that this unusual velocity scaling is not unique to the baseline configuration, similar velocity and frequency normalizations were used to collapse data for the 570 Rayl porous surface treatment applied at both inboard and outboard flap tips. The resulting plots are shown in Fig. 9. As was the case for the baseline configuration, the standard normalization based on $\mathrm{M}^{6}$ and $S t$ fails to collapse to a single curve (see Fig. 9b); $\mathrm{M}^{6}$ scaling without frequency normalization (Fig. 9c) yields better results. $\mathrm{M}^{4}$ scaling with $S t$ frequency normalization (Fig. 9d) provides the best data collapse. In Figs. $8 \mathrm{a}$ and 9a, notice the presence of a tone at $24 \mathrm{kHz}(\mathrm{M}=0.16$ PSD curve) and a minor tonal hump centered at $22.5 \mathrm{kHz}(\mathrm{M}=0.24 \mathrm{PSD}$ curve). Although the source of the peak at $24 \mathrm{kHz}$ is not known at this time, this feature also appears in the clean (cruise) configuration and therefore is not related to either the flap or the main landing gear. The minor tonal hump at $22.5 \mathrm{kHz}$ was found to be associated with the two middle flap bracket 
assemblies. Each assembly contains a ring-like element used to hold a worm gear in place. Because of installation difficulties, the worm gears were not installed during the $14 \times 22$ test, thus causing the two ring-like pieces to resonate as air flowed past them.

Velocity and frequency scaling results for the other installed flap noise reduction concepts follow those presented for the baseline and porous tip configurations, and thus are omitted here. Further analysis is required to determine the causes of the unexpected scaling behavior observed in this study.

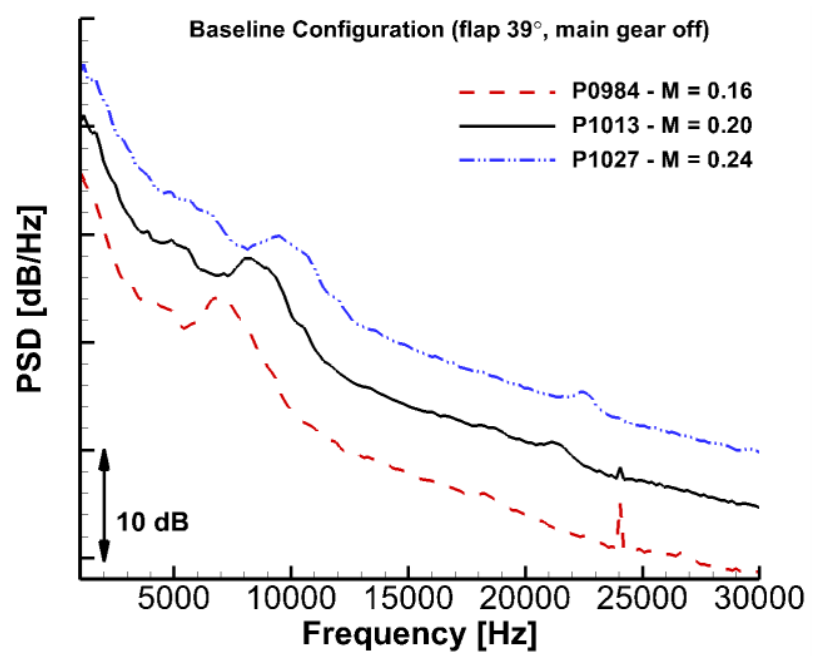

a) No scaling

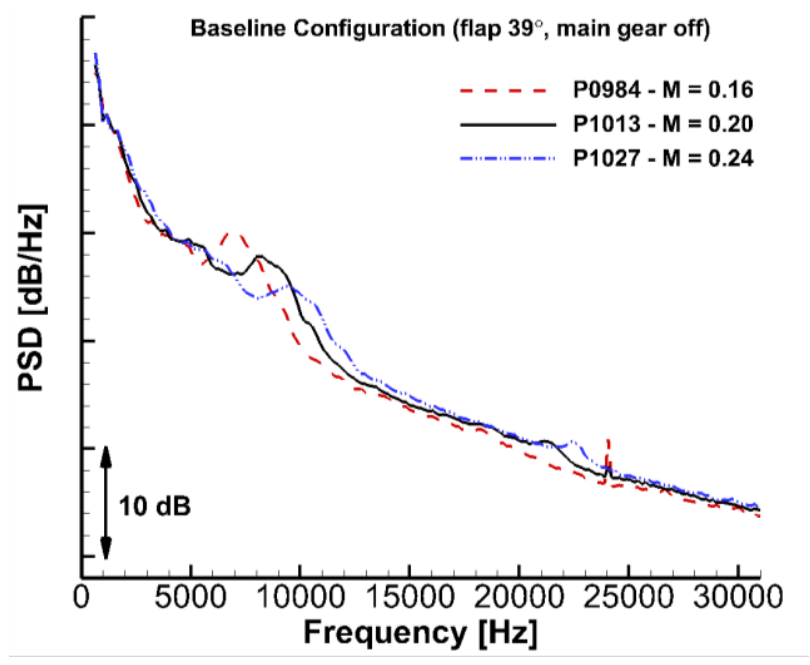

c) $\mathrm{M}^{6}$ without $S t$ frequency scaling

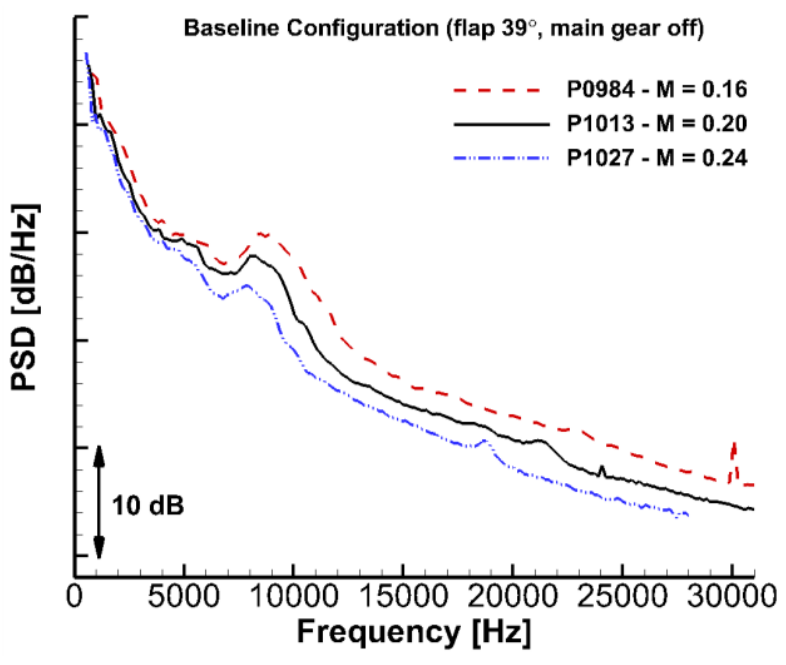

b) $\mathrm{M}^{6}$ and $S t$ frequency scaling

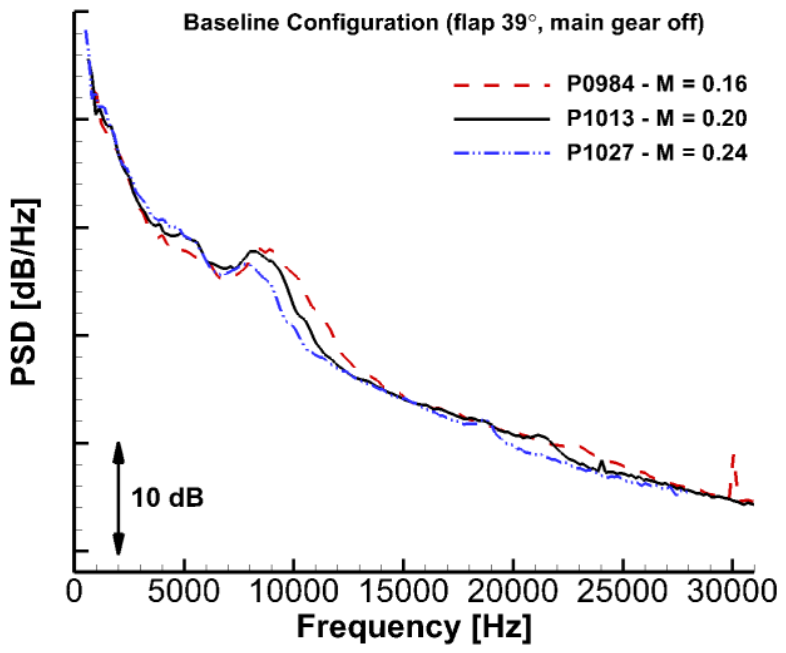

d) $\mathrm{M}^{4}$ with $S t$ frequency scaling

Figure 8. Velocity and frequency scaling of farfield noise for baseline configuration $(M=0.2$, overhead) 


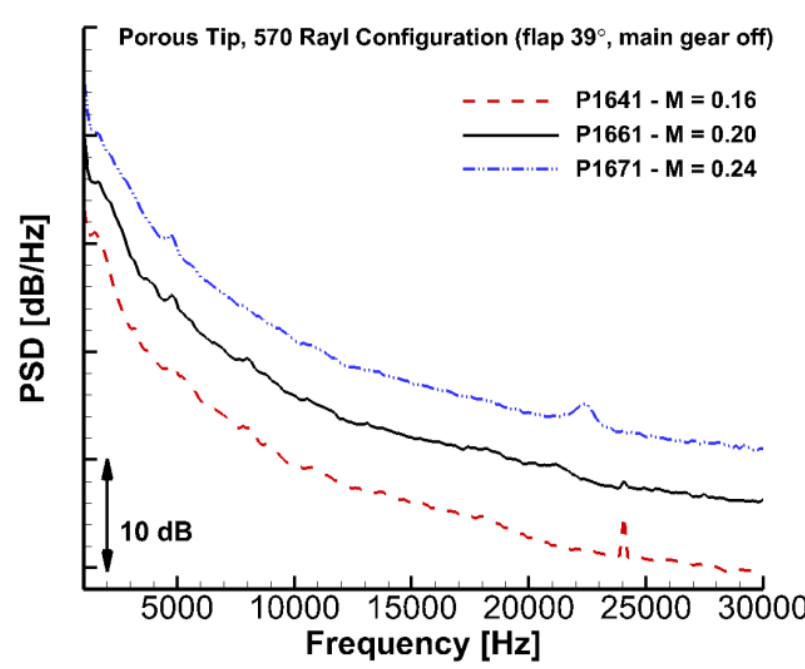

a) No scaling

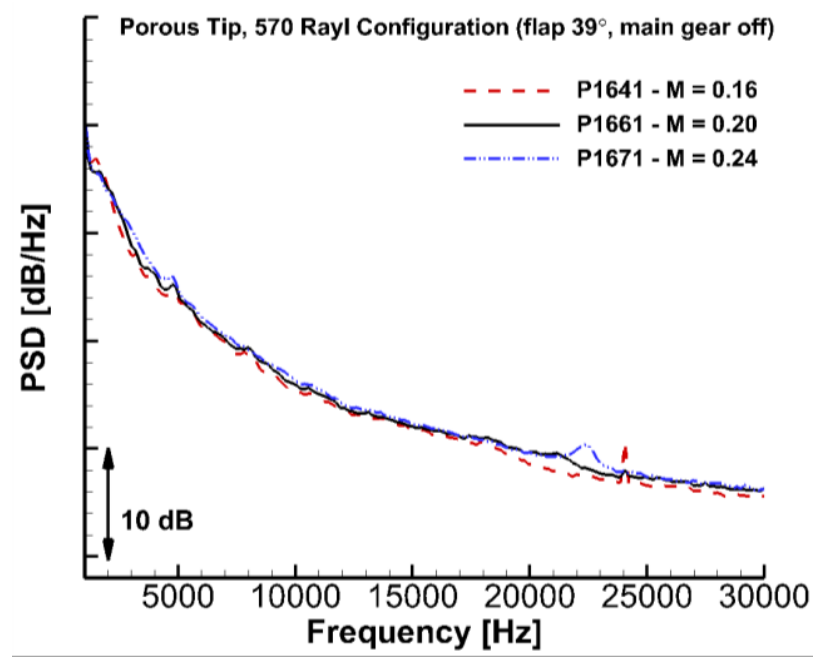

c) $\mathrm{M}^{6}$ without $S t$ frequency scaling

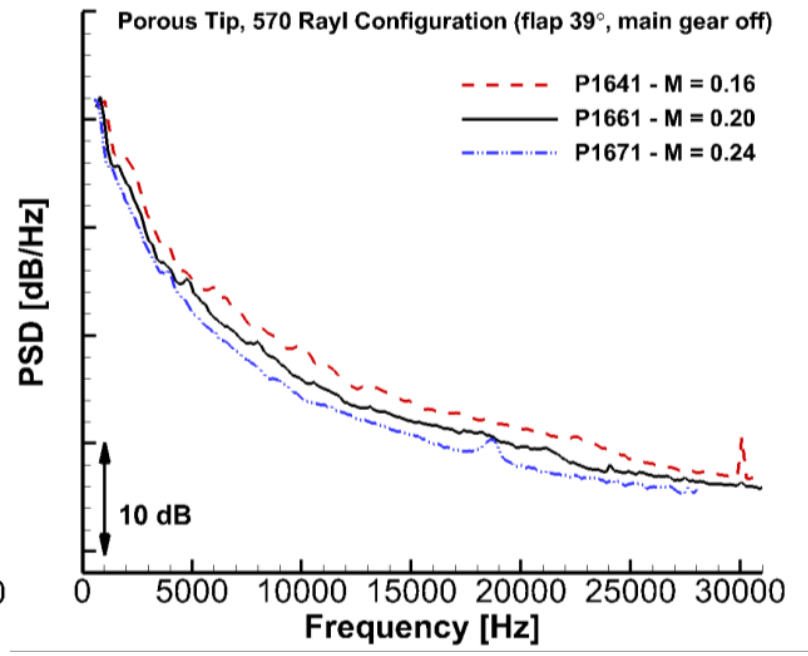

b) $\mathrm{M}^{6}$ and $S t$ frequency scaling

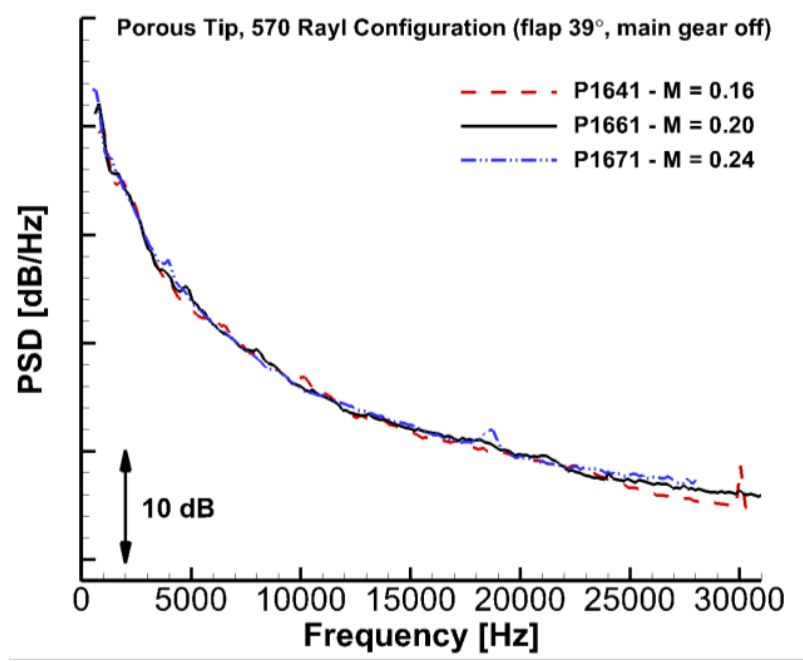

d) $\mathrm{M}^{4}$ with $S t$ frequency scaling

Figure 9. Velocity and frequency scaling of farfield noise for porous tip concept $(\mathrm{M}=0.2$, overhead $)$

\section{Directivity Patterns}

Unless stated otherwise, all data presented in this section correspond to $\mathrm{M}=0.2$ and $\mathrm{AOA}=3^{\circ}$. Farfield noise directivity for the baseline configuration is shown in Fig. 10. For clarity, only four of the tested angles covering a $50^{\circ}$ arc in the flyover direction are displayed. Throughout the paper, directivity corresponds to the array traversing locations and not along a constant radius. Overall, there are no drastic changes observed in the directivity of the radiated flap side-edge noise in the flyover direction. Because of the cavity resonance, the spectrum associated with the outboard tip zone (Fig. 10b) displays the largest observed variation with directivity angle for frequencies below $11 \mathrm{kHz}$. In contrast, the inboard tip spectrum (Fig. 10c) shows a very mild directivity change. The amplitudes have not been scaled based on the distance between the array and the model, so the levels at $90^{\circ}$ should be the highest if the directivity were perfectly uniform. The extra distance at $\pm 20^{\circ}$ accounts for a $0.5 \mathrm{~dB}$ difference, and $1.24 \mathrm{~dB}$ at $30^{\circ}$.

The effectiveness of the four selected flap noise reduction concepts has been demonstrated for the overhead $\left(90^{\circ}\right)$ position in Ref. 12. However, to substantially reduce the aircraft noise footprint on the ground during landing, the noise reduction concepts must perform well over a wide range of flyover angles. Acoustic performance of the four noise mitigation concepts (i.e., porous tip treatment, FENoRFins, FLEXSEL, and ROLD) within the $60^{\circ}-110^{\circ}$ range of flyover angles tested are assessed subsequently. 


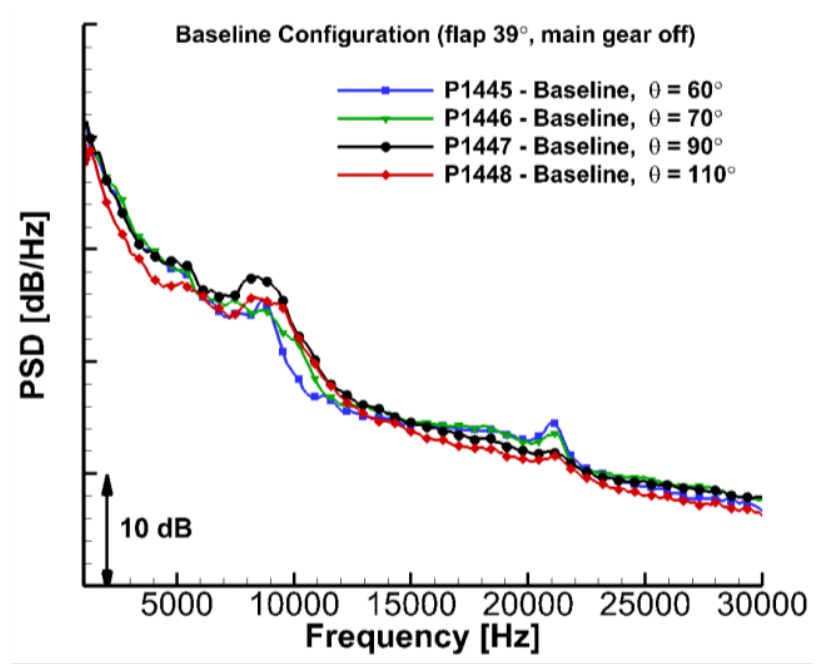

a) Region 1 (wing-flap)

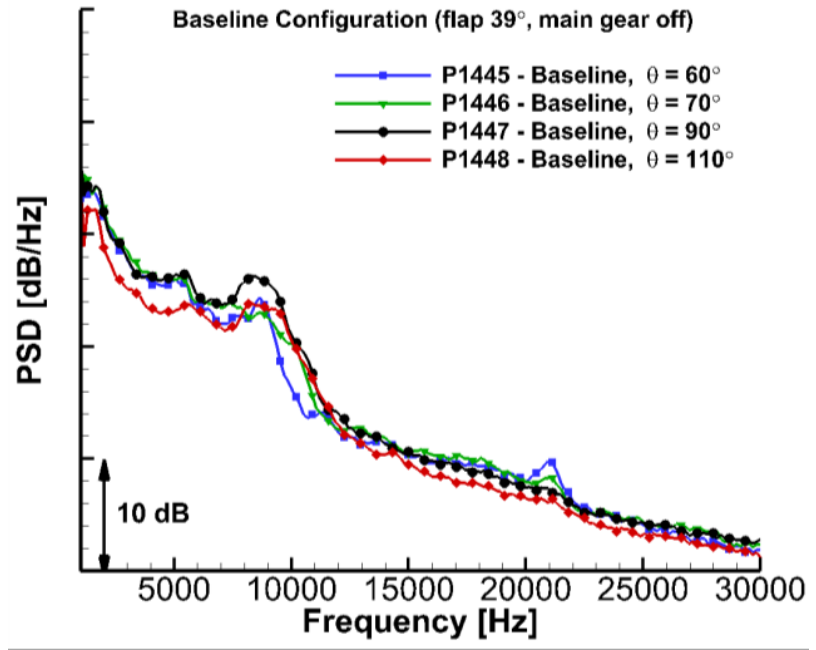

b) Region 2 (outboard flap tip)

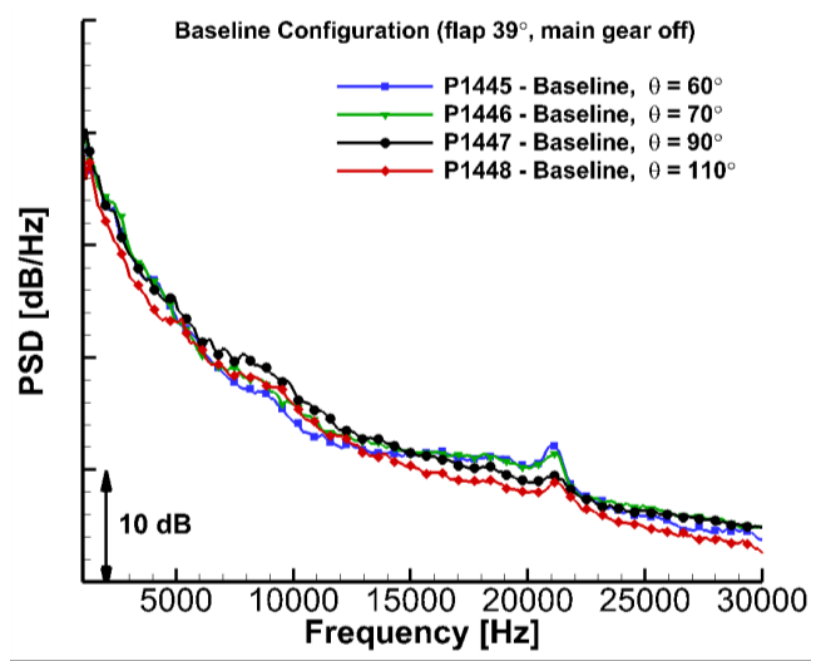

c) Region 3 (inboard flap tip)

Figure 10. Farfield noise directivity for baseline configuration $(M=0.2)$

Farfield noise directivity patterns for the 570 Rayl porous surface treatment are shown in Fig. 11. Results for the other resistances were similar, but the 570 Rayl case had the least aerodynamic penalty. The spectra from Region 1 (Fig. 11a) illustrate that this concept performs well over the range of angles measured, producing $3 \mathrm{~dB}$ or more of noise reduction at all frequencies. Note from Fig. 11b that the porous treatment performed very well at the outboard tip, reducing the pressure levels almost $4 \mathrm{~dB}$ for frequencies above $4 \mathrm{kHz}$. Noise reduction levels in excess of $4 \mathrm{~dB}$ observed at the outboard tip for frequencies in the $4-11 \mathrm{kHz}$ range are caused by removal of the tip cavity when the porous treatment or other flap concepts are applied. Nevertheless, a comparison of Figs. 11b and 11c indicates that, even without the tip cavity, the porous treatment seems to perform better at the outboard flap tip than the inboard edge. The decrease in measured noise reduction effectiveness of the porous concept at frequencies below $3 \mathrm{kHz}$ for both tips can partially be attributed to two factors: elevated tunnel background noise at low frequencies (see Ref. 12) and degradation of microphone array resolution for frequencies below $1.5 \mathrm{kHz}$.

Directivity plots of the farfield noise for the FENoRFins concept are displayed in Fig. 12. The spectra obtained from integration of Region 1 (Fig. 12a) shows a reduction in noise levels of approximately $3 \mathrm{~dB}$ for frequencies up to $13 \mathrm{kHz}$ over the range of angles tested. At higher frequencies, device (self) noise associated with FENoRFins becomes dominant $^{12}$ and rises above the noise levels for the baseline configuration. A comparison of the spectra in Figs. 12b and $12 \mathrm{c}$ reveals a behavior similar to that of the porous tip treatment. That is, the concept performs slightly better at the outboard tip than the inboard tip. The frequencies at which the device's self noise overtakes the baseline noise levels are around $18-19 \mathrm{kHz}$ for the outboard flap edge (Fig. 12b) and $14-15 \mathrm{kHz}$ for the inboard edge (Fig. 12c). 


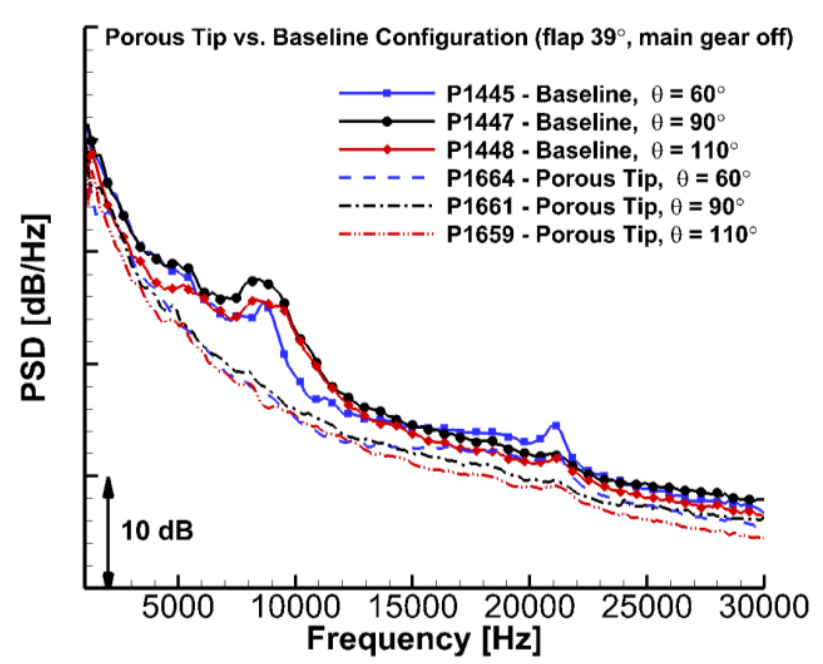

a) Region 1 (wing-flap)

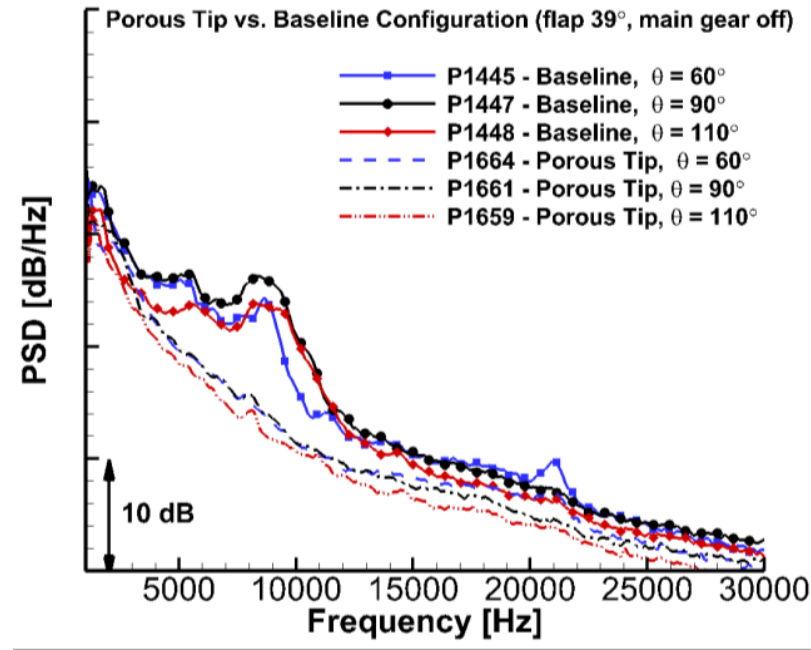

b) Region 2 (outboard flap tip)

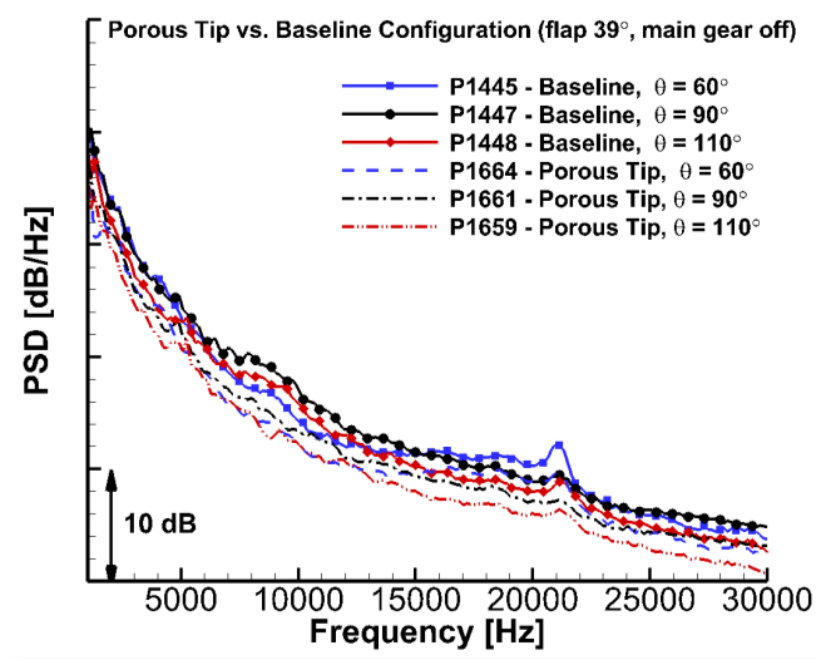

c) Region 3 (inboard flap tip)

Figure 11. Farfield noise directivity for porous tip concept $(M=0.2)$

Directivity plots for the FLEXSEL concept are shown in Fig. 13. As seen from the spectra in Fig. 13a, this side edge link design performs well at all flyover angles tested, producing $3 \mathrm{~dB}$ or more of noise reduction at most frequencies. As observed for the two previous concepts, FLEXSEL is more effective at the outboard tip than the inboard tip. The deterioration in the concept's measured performance at low frequencies could partially be attributed to the presence of tunnel background noise and degradation in microphone array frequency resolution.

Farfield noise directivity for the ROLD concept is presented in Fig. 14. The noise reduction characteristics and directivity behavior of this concept are very similar to those of the FENoRFins concept (see Fig. 12). Although ROLD shows slightly better noise reduction performance than FENoRFins, it also suffers from excessive device noise that is apparent at mid to high frequencies. ROLD performs well in the low to mid frequency range, particularly at the inboard flap tip zone (Region 3) where a noise reduction benefit in excess of $3 \mathrm{~dB}$ is observed at all measured angles. 


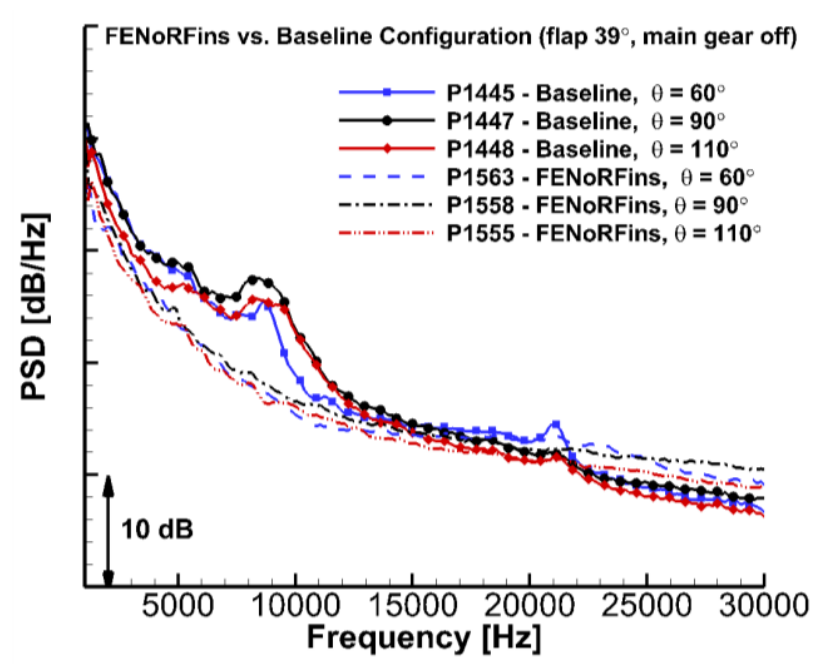

a) Region 1 (wing-flap)

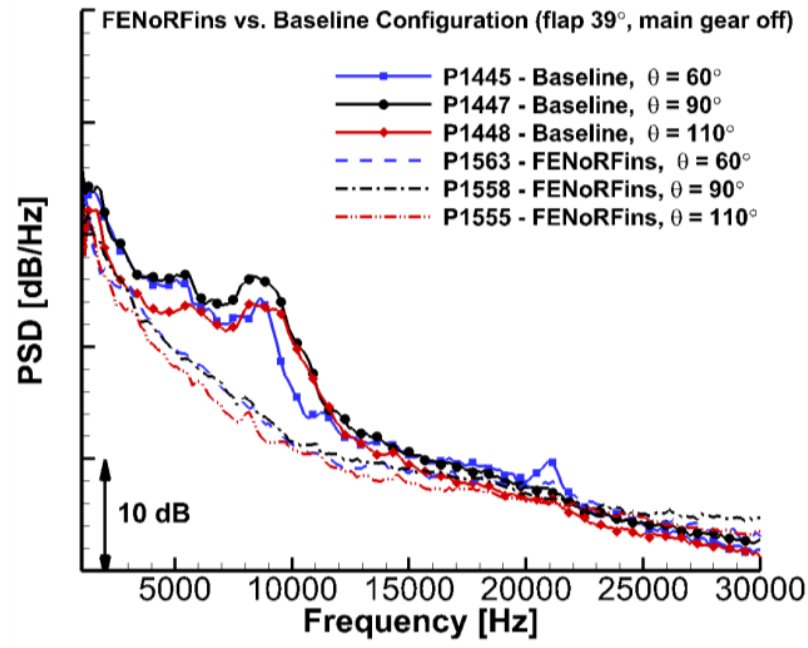

b) Region 2 (outboard flap tip)

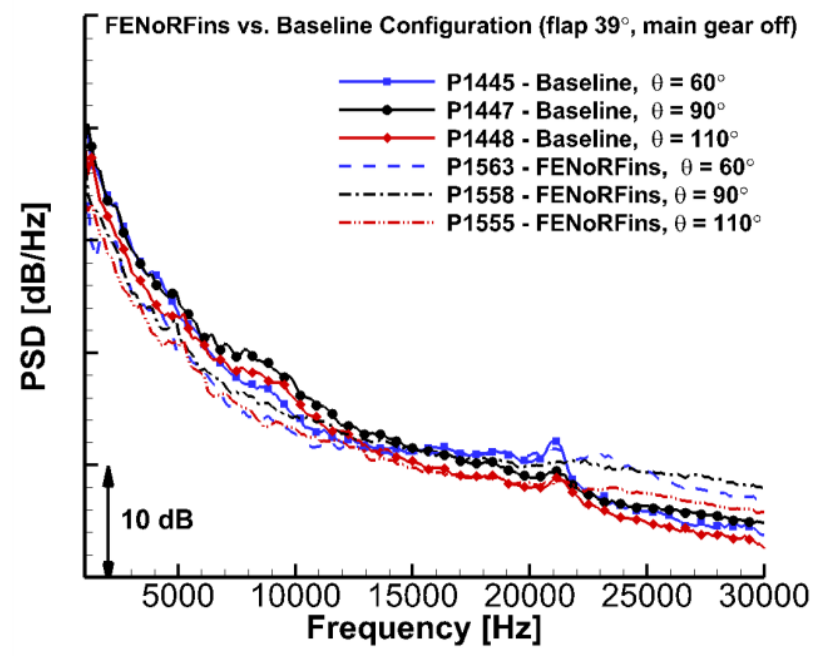

c) Region 3 (inboard flap tip)

Figure 12. Farfield noise directivity for FENoRFins concept $(M=0.2)$

The integrated spectra of the wing-flap zone (Region 1) at $90^{\circ}$ (overhead) for the baseline configuration and the four flap concepts considered in this study were converted to full-scale frequencies to calculate overall sound pressure levels (OASPL). Noise reduction benefits for each concept relative to the baseline flap configuration are presented in Table 1. Because of their similarity with perceived noise levels, D-weighted benefits are also included in the table.

Table 1. Acoustic performance of flap noise reduction concepts, $M=0.2$, overhead.

\begin{tabular}{|c|c|c|}
\hline \multirow{2}{*}{ Concept } & \multicolumn{2}{|c|}{ Noise benefit relative to baseline } \\
\cline { 2 - 3 } & Not weighted, dB & D-weighted, dBD \\
\hline Porous Tip (570 Rayl) & 3.60 & 3.64 \\
\hline FENoRFins & 4.28 & 3.21 \\
\hline FLEXSEL & 3.99 & 3.72 \\
\hline ROLD & 4.11 & 3.22 \\
\hline
\end{tabular}

Note from Table 1 that the four analyzed flap concepts produce noise reduction levels that fall within a very narrow range. This behavior may be influenced by inaccuracies in the acoustic measurements at low frequencies (i.e., 
tunnel background noise and array resolution effects) where the peak spectral levels occur and high frequencies because of flap bracket noise and decorrelation across the shear layer. These factors combine to create an artificially high noise floor that masks the true potential of the noise reduction concepts.

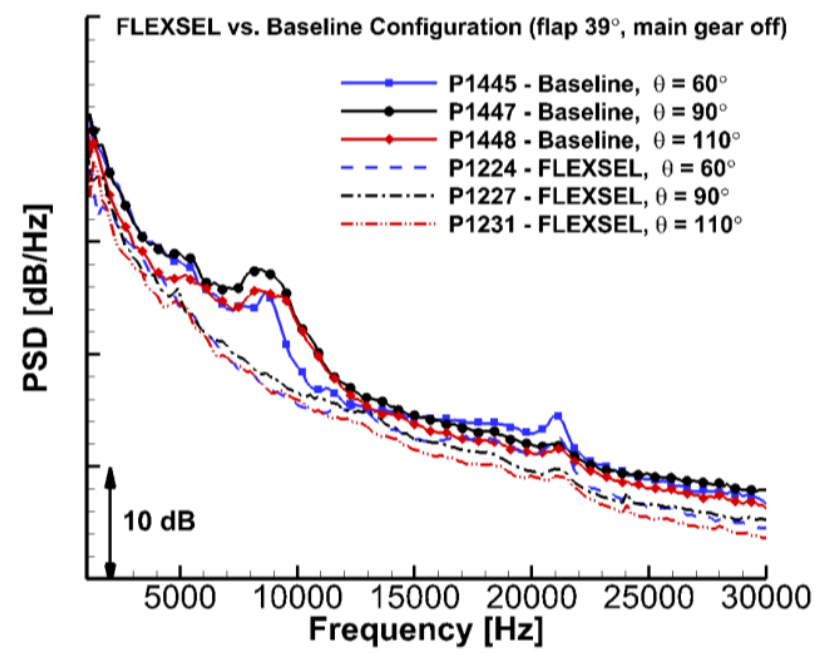

a) Region 1 (wing-flap)

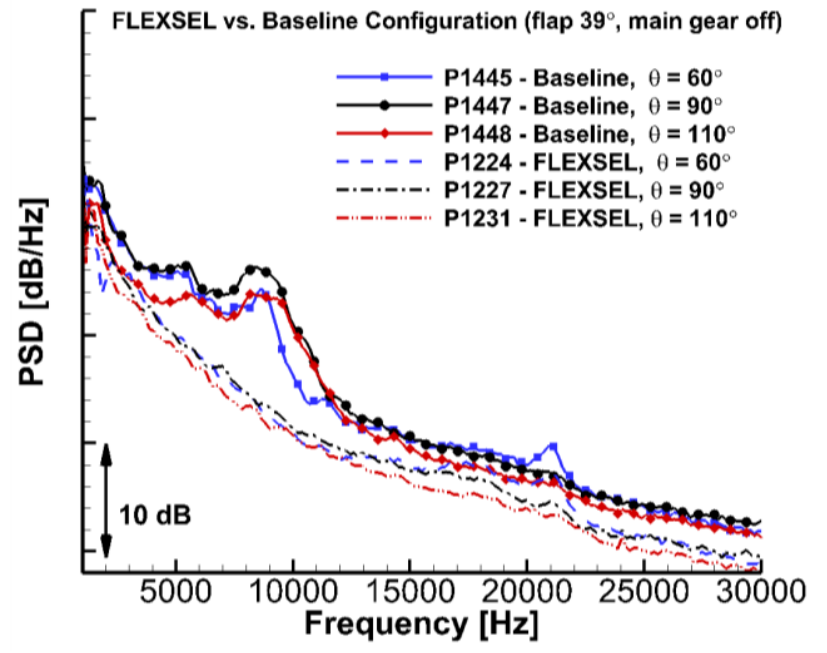

b) Region 2 (outboard flap tip)

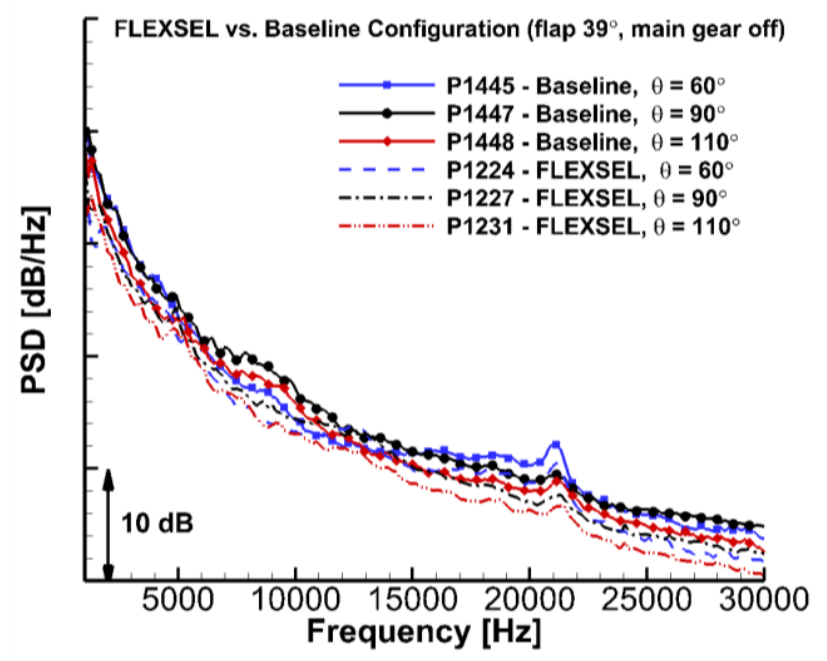

c) Region 3 (inboard flap tip)

Figure 13. Farfield noise directivity for FLEXSEL concept $(M=0.2)$ 


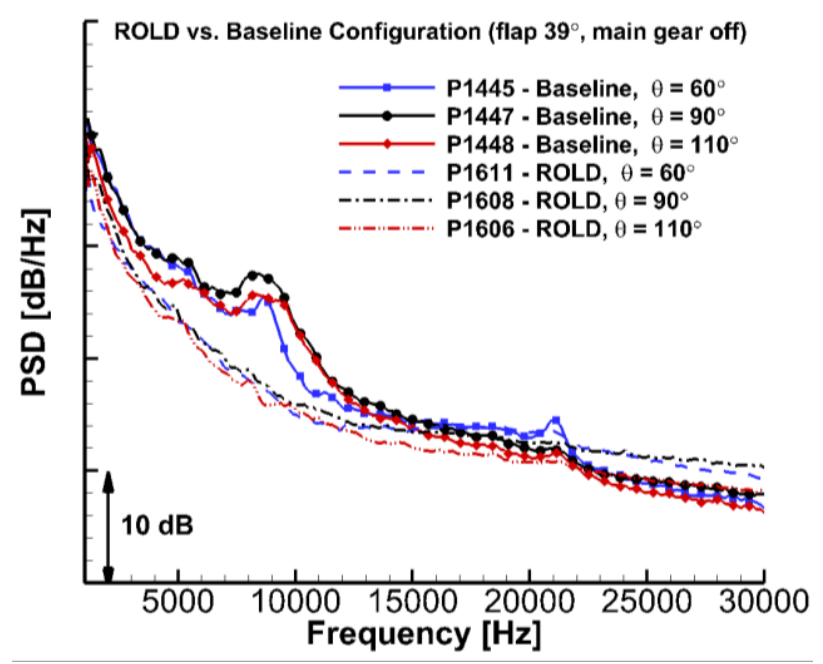

a) Region 1 (wing-flap)

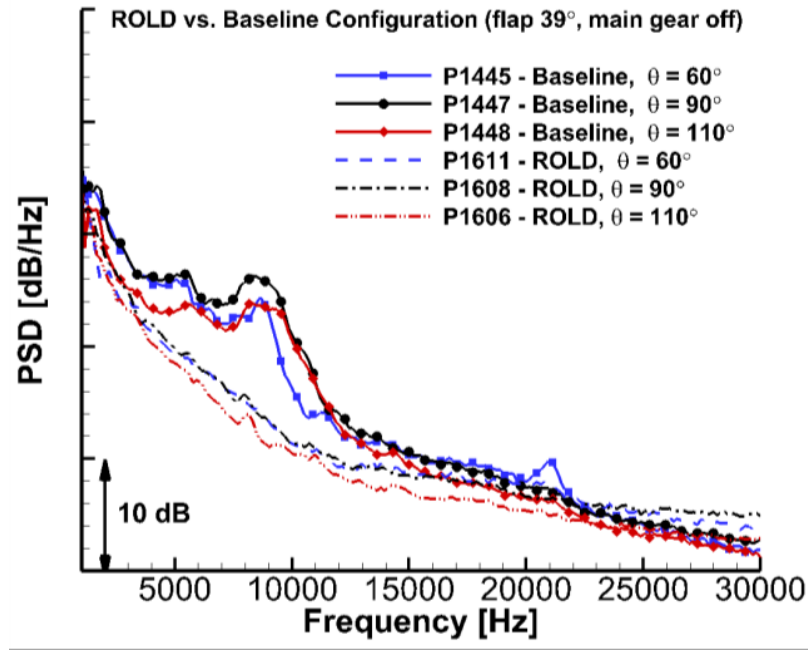

b) Region 2 (outboard flap tip)

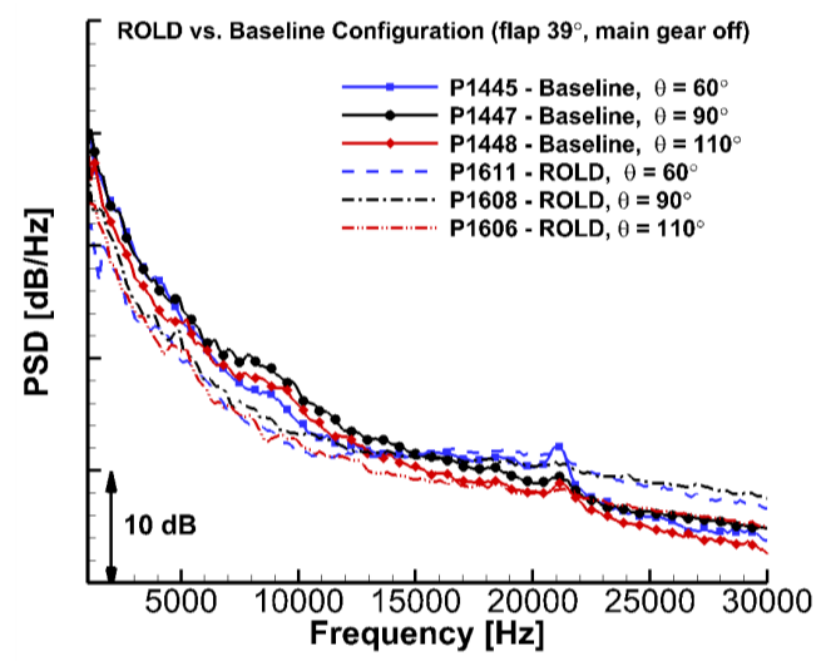

c) Region 3

Figure 14. Farfield noise directivity for ROLD concept $(M=0.2)$

\section{B. $39^{\circ}$ Flap with Main Gear Installed}

The configuration with $39^{\circ}$ flap and main gear on was used for concurrent evaluation of flap and gear noise reduction concepts on the full semi-span aircraft model in the landing configuration.

\section{AOA Effects}

Region 1 (wing-flap) PSD plots for the baseline configuration at $\mathrm{M}=0.2$ and $90^{\circ}$ (overhead) position are shown in Fig. 15. As was the case for the deflected flap with gear off configuration, the farfield noise spectrum remains virtually unchanged for the three AOAs measured. Similarly insensitive behavior to AOA variation was observed when different combinations of flap and gear noise reduction concepts were applied concurrently; therefore, those comparisons will not be displayed here. 


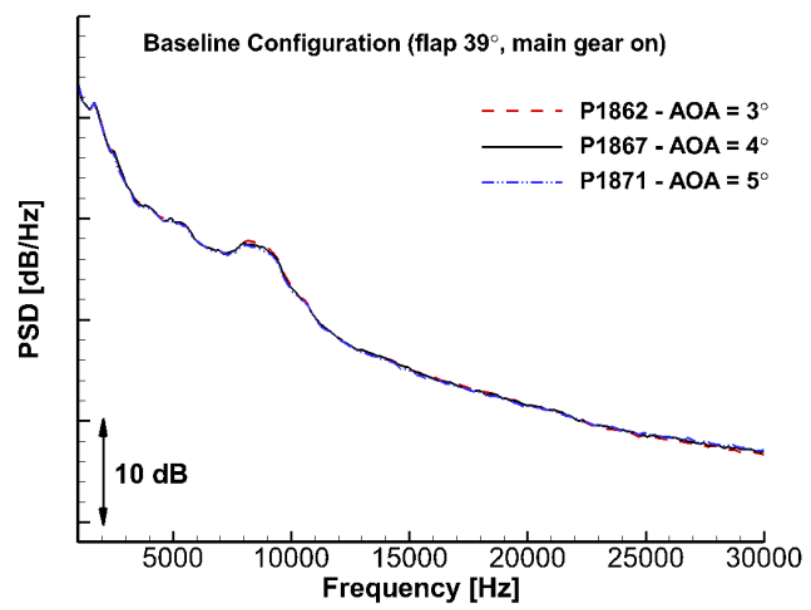

Figure 15. Effects of AOA variation on farfield noise for baseline configuration $(\mathrm{M}=0.2$, overhead)

\section{Velocity Scaling}

Farfield noise spectra associated with Region 1 (wing-flap) for the three flow speeds tested are shown in Fig. 16. For the present case, we have applied the same combinations of Mach number and $S t$ frequency scaling that were tried for the gear-off baseline configuration (Fig. 8). As seen from Fig. 16b, the standard $\mathrm{M}^{6}$ scaling in conjunction with $S t$ based frequency normalization fails to collapse the PSD curves. A much better normalization of the spectra is obtained when $\mathrm{M}^{6}$ scaling alone is applied (Fig. 16c). Again, the combination of $\mathrm{M}^{4}$ and $S t$ scaling produces the best data collapse (Fig. 16d), indicating that the combined noise sources associated with the flap and gear follow similar velocity scaling as those of the flap. Similar velocity and frequency scaling results (not shown) were observed when flap and gear noise reduction concepts were applied concurrently.

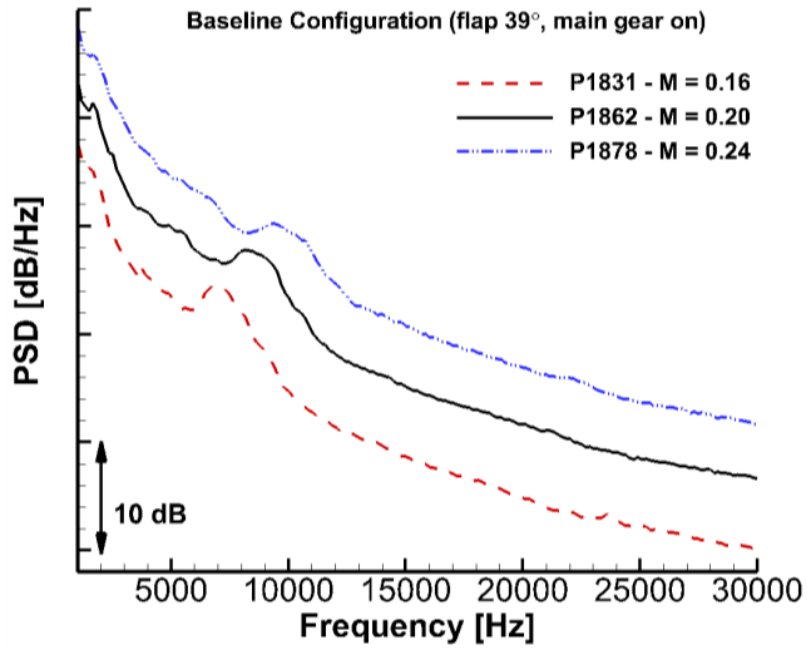

a) No scaling

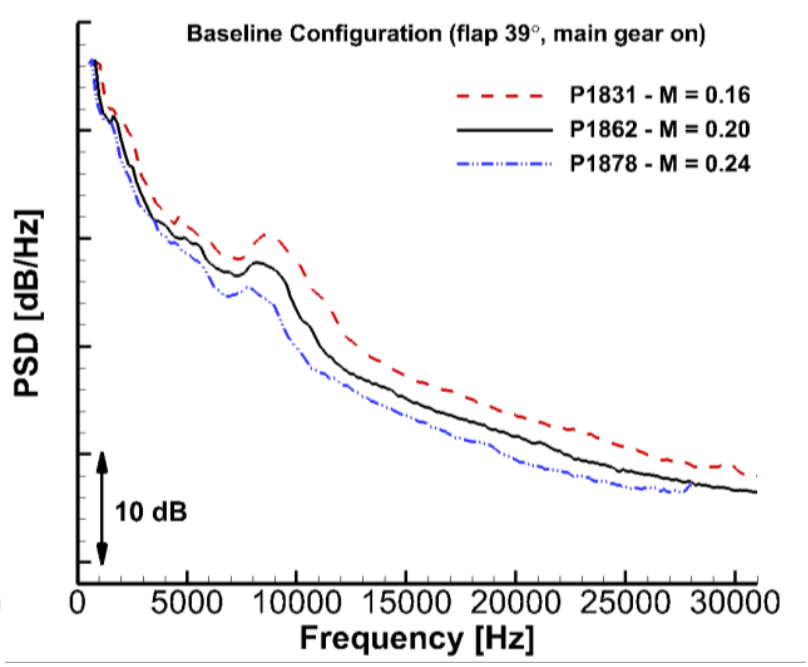

b) $\mathrm{M}^{6}$ and $S t$ frequency scaling

Figure 16. Velocity and frequency scaling of farfield noise for baseline configuration $(M=0.2$, overhead) 


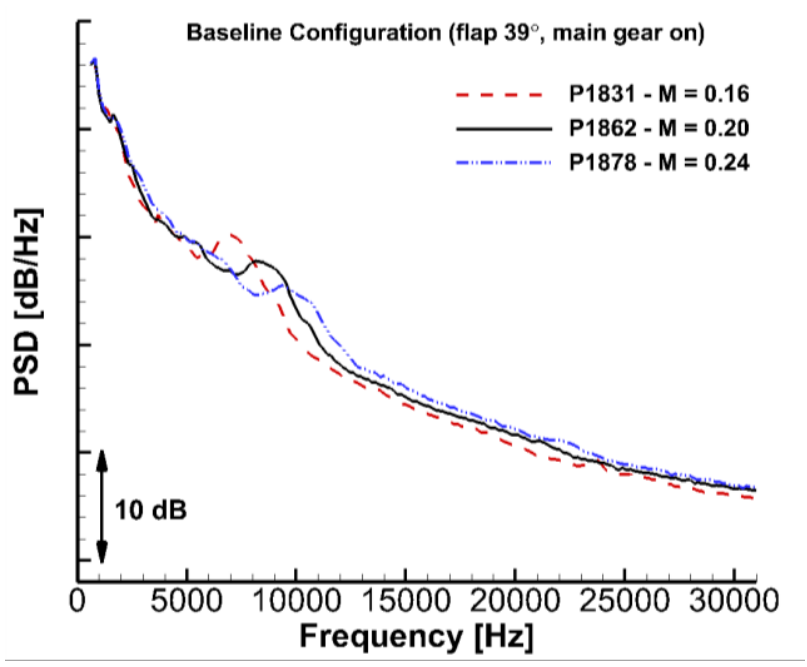

c) $\mathrm{M}^{6}$ without $S t$ frequency scaling

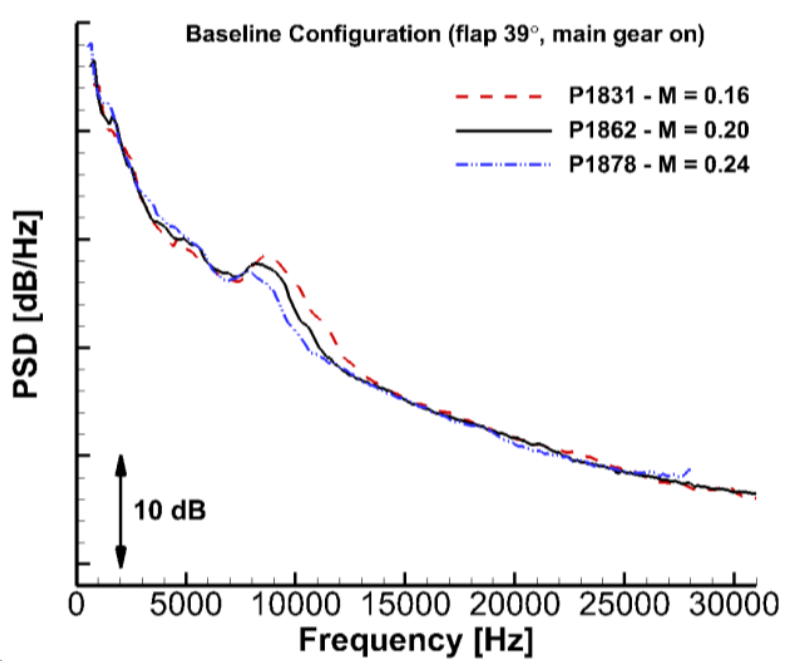

d) $\mathrm{M}^{4}$ with $S t$ frequency scaling

Figure 16. Concluded

\section{Directivity Patterns}

In this section, we present the directivity of the farfield noise relative to the baseline case for two configurations with noise abatement technology applied to both flap and gear components. In the first configuration, the flap tip was modified to incorporate the 570 Rayl porous treatment, and the gear assembly included a collection of upper fairings (UF), porous knee fairing (PKF), wheel fairing (WF), and stretchable cavity mesh (SCM). The second configuration is very similar to the first, except that it lacks the wheel fairing.

Farfield noise directivity for configuration 1 (porous tip $+\mathrm{UF}+\mathrm{PKF}+\mathrm{WF}+\mathrm{SCM}$ ) for $\mathrm{M}=0.2$ and $\mathrm{AOA}=3^{\circ}$ is shown in Fig. 17. Only contributions from Region 1 (wing and flap) are presented. Given the close proximity of the inboard flap tip to the main gear, spectra obtained from Regions 2 and 3 cannot be used to separate gear and flap contributions to the farfield noise. As seen from Fig. 17, this combination of flap and gear concepts produces good noise reduction benefits on the order of 2.0 to $2.5 \mathrm{~dB}$ across the entire range of frequencies and flyover angles of interest.

PSD plots for configuration 2 (porous tip + UF + PKF + SCM) are shown in Fig. 18. The absence of a wheel fairing has a noticeable effect on the noise reduction levels over most frequencies. In particular, in the rear quadrant $\left(\theta=110^{\circ}\right)$, there is hardly any reduction in noise levels at frequencies below $4 \mathrm{kHz}$. This observation suggests that gear cavity noise is confined mainly to the flyover angles in the forward quadrant $\left(\theta\right.$ less than $\left.90^{\circ}\right)$. As a result, the stretchable cavity mesh and other devices are not providing any measurable benefits at low frequencies for $\theta>100^{\circ}$.

PSD data at $\theta=90^{\circ}$ (overhead position) for the two acoustically treated configurations considered here (Figs. 17 and 18) were converted to full scale levels and frequencies. Noise reduction benefits (not weighted and D-weighted) for each configuration relative to the baseline $39^{\circ}$ flap deflection with gear installed configuration are presented in Table 2. Note from the table that configuration 1 (wheel fairing on) yields a $2.85 \mathrm{dBD}$ benefit as compared to a 2.79 $\mathrm{dBD}$ benefit for configuration 2 (wheel fairing off).

Table 2. Acoustic performance of flap/gear noise reduction concepts, $M=0.2$, overhead.

\begin{tabular}{|c|c|c|}
\hline \multirow{2}{*}{ Concept } & \multicolumn{2}{|c|}{ Noise benefit relative to baseline } \\
\cline { 2 - 3 } & Not weighted, dB & D-weighted, dBD \\
\hline Configuration 1 & 2.49 & 2.85 \\
\hline Configuration 2 & 2.48 & 2.79 \\
\hline
\end{tabular}




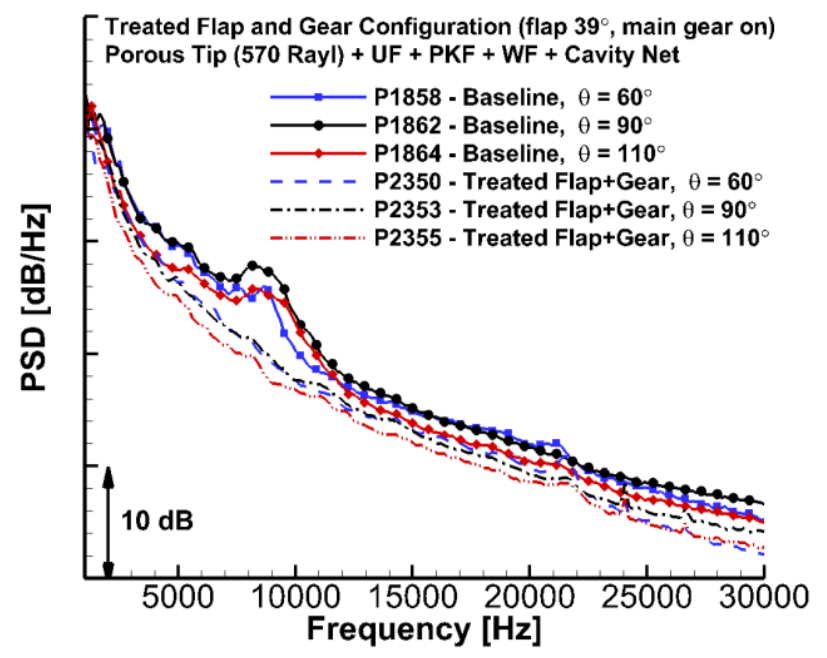

Figure 17. Farfield noise directivity for treated gear and flap $(M=0.2$, Region 1, configuration 1)

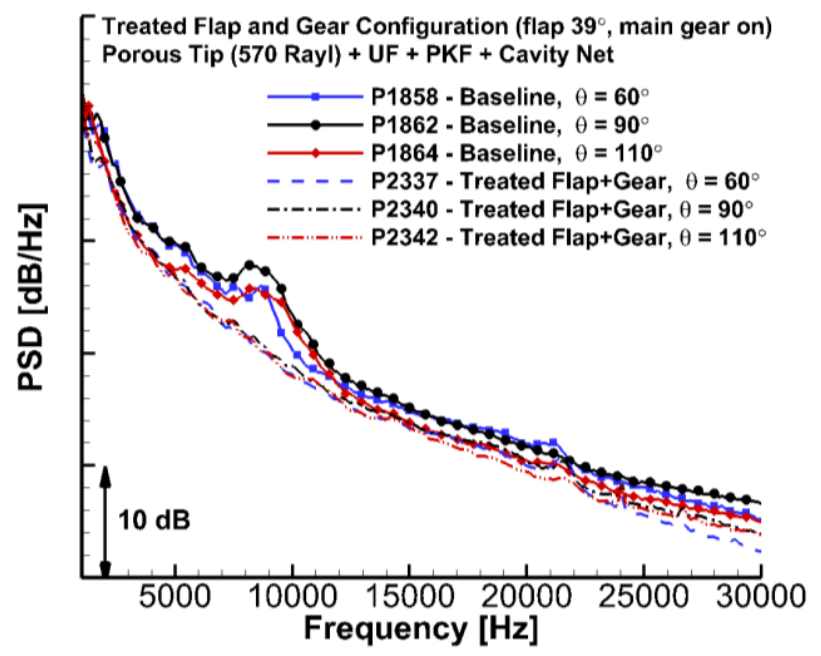

Figure 18. Farfield noise directivity for treated gear and flap $(M=0.2$, Region 1, configuration 2)

\section{Concluding Remarks}

The present analysis is a continuation of an earlier experimental effort (Ref. 12) focused on the aeroacoustic evaluation of several noise abatement concepts for flaps and main landing gear using an 18\% scale, semi-span, Gulfstream aircraft model as test bed. For a configuration where the flap was deflected $39^{\circ}$ and the main gear retracted, the effectiveness of four tip treatment concepts in reducing flap side edge noise was assessed in detail. Farfield noise spectra were shown to be insensitive to AOA variation for the range of angles typically used during aircraft landing. Velocity and frequency normalizations based on $\mathrm{M}^{6}$ and $S t$, respectively, which are typical for airframe noise applications, failed to collapse the farfield spectra obtained at $\mathrm{M}=0.16,0.2$, and 0.24 . Alternative scaling approaches using $\mathrm{M}^{6}$ without frequency normalization and $\mathrm{M}^{4}$ with $S t$ normalization were shown to produce much better results. The causes and ramifications of these unusual scaling are not fully understood and require further scrutiny. Farfield directivity characteristics for the flap concepts in the flyover directionfrom $60^{\circ}$ to $110^{\circ}$ were considered. In general, all four concepts were found to perform well at low to mid frequencies. The porous tip and FLEXSEL treatments yielded the largest noise benefits in terms of D-weighted OASPL, primarily because they did not suffer from increased self-noise at high frequencies. Relative to the baseline configuration, the tip treatments were between 3.2 to $3.7 \mathrm{dBD}$ quieter. In general, the noise reduction capability of the concepts was maintained over the measured flyover angles, demonstrating their ability to positively affect aircraft noise foot print on the ground during landing.

For the main landing gear, two quiet configurations in conjunction with the 570 Rayl porous tip treatment were considered. Configuration 1 comprised the upper fairings, porous knee fairing, stretchable cavity mesh, and wheel 
fairing; configuration 2 excluded the wheel fairing. The farfield noise spectra associated with a configuration with the flap deflected $39^{\circ}$ and gear deployed were insensitive to AOA variation, as was the case for the isolated flap. Similarly, $\mathrm{M}^{6}$ without $S t$ and $\mathrm{M}^{4}$ with $S t$ normalization provided better measured farfield data collapse for $\mathrm{M}=0.16,0.2$, and 0.24. Directivity plots revealed that both quiet gear configurations yield relatively good noise reduction performance over the range of flyover angles tested. A comparison between the two gear configurations indicated that the wheel fairing has a noticeable effect in reducing noise at low and high frequencies.

\section{Acknowledgments}

This work was supported by the Environmentally Responsible Aviation (ERA) project under the Integrated System Research Program (ISRP) of NASA.

\section{References}

${ }^{1}$ Dobrzynski, W., “Almost 40 Years of Airframe Noise Research: What Did We Achieve,” J. Aircraft, Vol. 47, No. 2, MarchApril 2010, pp. $353-367$.

${ }^{2}$ Michel, U., Barsikow, B., Helbig, J., Hellmig, M., and Schüttpelz, M., "Flyover Noise Measurements on Landing Aircraft with a Microphone Array," AIAA Paper 98-2336, May 1998.

${ }^{3}$ Piet, J.-F., Elias, G., and Lebigot, P., "Localization of Acoustic Sources from a Landing Aircraft with a Microphone Array," AIAA Paper 99-1811, May 1999. 999.

Michel, U. and Qiao, W., "Directivity of Landing-Gear Noise Based on Flyover Measurements," AIAA Paper 99-1956, May

${ }^{5}$ Pott-Pollenske, M., Dobrzynski, W., Buchholz, H., Gehlhar, B., and Walle, F., "Validation of a Semiempirical Airframe Noise Prediction Method through Dedicated A319 Flyover Noise Measurements," AIAA Paper 2002-2470, May 2002.

${ }^{6}$ Stoker, R., Guo, Y., Streett, C., and Burnside, N., "Airframe Noise Source Locations of a 777 Aircraft in Flight and Comparisons with Past Model Tests," AIAA Paper 2003-3232, May 2003.

${ }^{7}$ Sijtsma, P. and Stoker, R., "Determination of Absolute Contributions of Aircraft Noise Components Using Fly-Over Array Measurements," AIAA Paper 2004-2958, May 2004.

${ }^{8}$ Piet, J.-F., Davy, R., Elias, G., Siller, H. A., Chow, L. C., Seror, C., and Laporte, F., "Flight Test Investigation of Add-On Treatments to Reduce Aircraft Airframe Noise," AIAA Paper 2005-3007, May 2005.

${ }^{9}$ Horne, W. C., James, K. D., Arledge, T. K., Soderman, P. T., Burnside, N., and Jaeger, S. M., "Measurements of 26\%-Scale 777 Airframe Noise in the NASA Ames 40- by 80-Foot Wind Tunnel," AIAA Paper 2005-2810, May 2005.

${ }^{10}$ Elkoby, R., Brusniak, L., Stoker, R., Khorrami, M. R., Abeysinghe, A., and Moe, J.W., "Airframe Noise Results from the QTD II Flight Test Program,” AIAA Paper 2007-3457, May 2007.

${ }^{11}$ Khorrami, M. R., Lockard, D. P., Humphreys, Jr., W. M., Choudhari, M. M., and Van de Ven, T., "Preliminary Analysis of Acoustic Measurements from the NASA-Gulfstream Airframe Noise Flight Test,” AIAA Paper 2008-2814, May 2008.

${ }^{12}$ Khorrami, M. R., Humphreys, Jr. W. M.., Lockard, D. P., and Ravetta, P. A., “Aeroacoustic Evaluation of Flap and Landing Gear Reduction Concepts," AIAA Paper 2014-2478, June 2014.

${ }^{13}$ Neuhart, D. H., Hannon, J. A., and Khorrami, M. R., "Aerodynamic Measurements of a Gulfstream Aircraft Model with and without Noise Reduction Concepts," AIAA Paper 2014-2477, June 2014.

${ }^{14}$ Khorrami, M. R., Hannon, J. A., Neuhart, D. H., Markowski, G. A., and Van de Ven, T., "Aeroacoustic Studies of a HighFidelity Aircraft Model: Part 1- Steady Aerodynamic Measurements,” AIAA Paper 2012-2233, June 2012.

${ }^{15}$ Khorrami, M. R. and Neuhart, D. H, "Aeroacoustic Studies of a High-Fidelity Aircraft Model: Part 2-Unsteady Surface Pressures," AIAA Paper 2012-2234, June 2012.

${ }^{16}$ Brooks, T. F., and Humphreys, Jr., W. M., “A Deconvolution Approach for the Mapping of Acoustic Sources (DAMAS) Determined from Phased Microphone Arrays," J. of Sound and Vibration, Vol. 294, pp. 856 - 879, 2006.

${ }^{17}$ Brooks, T. F., and Humphreys, Jr., W. M., "Extension of DAMAS Phased Array Processing for Spatial Coherence Determination (DAMAS-C)," AIAA Paper 2006-2654, May 2006.

${ }^{18}$ Humphreys, Jr., W. M., Brooks, T. F., Bahr, C. J., Spalt, T. B., Bartram, S. M., Culliton, W. G., and Becker, L. E., "Development of a Microphone Phased Array Measurement Capability for the Langley 14 by 22 Foot Subsonic Tunnel," AIAA Paper 2014-2343, June 2014.

${ }^{19}$ Khorrami, M. R. and Mineck, R. E., “Towards Full-Aircraft Airframe Noise Prediction: Detached Eddy Simulations,” AIAA Paper 2014-2480, June 2014.

${ }^{20}$ Khorrami, M. R., Fares, E., and Casalino, D., “Towards Full-Aircraft Airframe Noise Prediction: Lattice-Boltzmann Simulations," AIAA Paper 2014-2481, June 2014. 
${ }^{21}$ Fares, E., and Casalino, D., and Khorrami, M. R., "Evaluation of Airframe Noise Reduction Concepts via Simulations using a Lattice-Boltzmann Approach," Paper to be presented at the $21^{\text {st }}$ AIAA/CEAS Aeroacoustics Conference in Dallas Texas, June 2015.

${ }^{22}$ Berkman, M. E., Khorrami, M. R., Choudhari, M., and Sadowski, S. S., "Investigation of High-Lift Flowfield of an Energy Efficient Transport Wing,” Journal of Aircraft, Vol. 37, No. 1, January-February 2000, pp. 45 - 52.

${ }^{23}$ Casalino, D., Fares, E., Duda, B., Hazir, A., and Khorrami, M. R., "On the Connection between Flap Side-Edge Noise and Tip Vortex Dynamics," Paper to be presented at the 21 ${ }^{\text {st }}$ AIAA/CEAS Aeroacoustics Conference in Dallas Texas, June 2015. 